
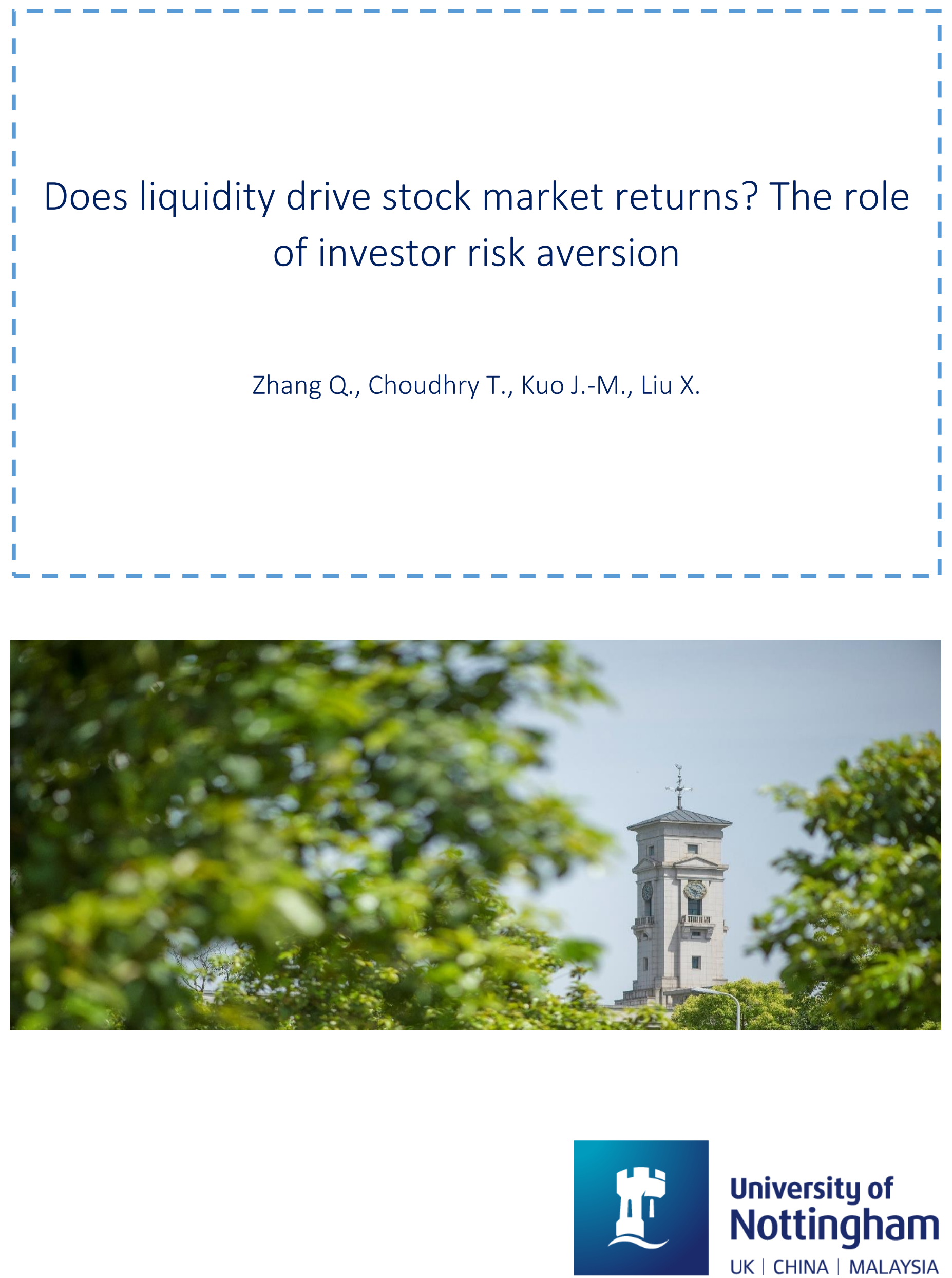

University of Nottingham 
University of Nottingham Ningbo China, 199 Taikang East Road, Ningbo, 315100, China

First published 2021

This work is made available under the terms of the Creative Commons Attribution 4.0 International License:

http://creativecommons.org/licenses/by/4.0

The work is licenced to the University of Nottingham Ningbo China under the Global University Publication Licence:

https://www.nottingham.edu.cn/en/library/documents/researchsupport/global-university-publications-licence.pdf Nottingham 


\title{
Does liquidity drive stock market returns? The role of investor risk aversion
}

\author{
Qingjing Zhang ${ }^{1}$, Taufiq Choudhry ${ }^{1}$, Jing-Ming Kuo ${ }^{2}$, Xiaoquan Liu*,3
}

\begin{abstract}
In this paper, we explore the relations between liquidity, stock returns, and investor risk aversion as captured by the variance risk premium (VRP). This is motivated by theoretical and empirical evidence in the literature which suggests that investor risk aversion negatively correlates with asset liquidity, and ample empirical evidence documenting liquidity risk premium. We use monthly US data from January 1999 to December 2018 and show that innovations in the VRP Granger-cause stock returns, which in turn drive liquidity. Our findings are consistent with predictions of prior theories and highlight the predictability of the VRP. They also contribute to the on-going debate on the causal relation between stock returns and liquidity. Finally, we explore the channels through which the VRP impacts liquidity and find that the VRP influences market and momentum factors, and that movements in these factors lead to changes in liquidity.
\end{abstract}

Keywords: Systematic factors; Toda-Yamamoto Granger non-causality test; Investor risk aversion; Liquidity.

JEL Classification : C32; C53; G12; G13; G14.

\footnotetext{
* Corresponding author.

E-mail addresses: Q.Zhang@soton.ac.uk (Qingjing Zhang); T.Choudhry@soton.ac.uk (Taufiq Choudhry); J.Kuo.2@bham.ac.uk (Jing-Ming Kuo);Xiaoquan.Liu@ nottingham.edu.cn (Xiaoquan Liu).

ORCID numbers: 0000-0001-8239-0070 (Qingjing Zhang); 0000-0002-0463-0662 (Taufiq Choudhry); 00000002-1205-0609 (Jing-Ming Kuo); 0000-0002-1765-4524 (Xiaoquan Liu).

1 Southampton Business School, University of Southampton, Southampton SO17 1BJ, UK

2 Birmingham Business School, University of Birmingham, Birmingham B15 2TY, UK

3 University of Nottingham Business School China, University of Nottingham, Ningbo 315100, China

Declaration:

Conflicts of interest: The authors declare that they have no known competing financial interests or personal relationships that could have appeared to influence the work reported in this paper.
} 


\title{
Does liquidity drive stock market returns? The role of the variance risk premium
}

\author{
February, 2021
}

\begin{abstract}
In this paper, we explore the relations between liquidity, stock returns, and investor risk aversion as captured by the variance risk premium (VRP). This is motivated by theoretical and empirical evidence in the literature which suggests that investor risk aversion negatively correlates with asset liquidity, and ample empirical evidence documenting liquidity risk premium. We use monthly US data from January 1999 to December 2018 and show that innovations in the VRP Granger-cause stock returns, which in turn drive liquidity. Our findings are consistent with predictions of prior theories and highlight the predictability of the VRP. They also contribute to the on-going debate on the causal relation between stock returns and liquidity. Finally, we explore the channels through which the VRP impacts liquidity and find that the VRP influences market and momentum factors, and that movements in these factors lead to changes in liquidity.
\end{abstract}

JEL classification: C32; C53; G12; G13; G14.

Keywords: Systematic factors; Toda-Yamamoto Granger non-causality test; Investor risk aversion; Liquidity. 


\section{Introduction}

The relation between risk and expected asset returns is at the centre of financial economics literature (Merton 1973). Despite close scrutiny and the consensus on liquidity as a risk factor (e.g., Pástor and Stambaugh 2003; Liu 2006), whether liquidity drives or is driven by stock returns is still being debated. Many studies argue that liquidity is able to predict future stock returns because of changes in transaction costs or behavioural biases such as over-optimism (e.g., Glosten and Milgrom 1985; Brennan and Subrahmanyam 1996; Lesmond et al. 1999; Jones 2002; Baker and Stein 2004; Bekaert et al. 2007). However, there also exists theoretical and empirical evidence that trading activities follow large absolute price changes or shocks to stock returns (e.g., Gallant et al. 1992; Hiemstra and Jones 1994; Chordia et al. 2001; Statman et al. 2006; Griffin et al. 2007; Hameed et al. 2010). Answers to this question are essential for advancing our understanding of the determinants of liquidity and asset returns as well as the relationship between them.

Meanwhile, the literature has seen extensive empirical evidence that the variance risk premium (hereafter VRP) can explain a sizeable proportion of stock market returns (e.g., Bollerslev et al. 2009, 2011, 2014; Drechsler and Yaron 2011; Feunou et al. 2018; Hollstein and Simen 2020). Theoretically, the VRP is induced by consumption uncertainty related to macroeconomic uncertainty and can be considered a measure of risk aversion for the representative agent (Rosenberg and Engle 2002; Bakshi and Madan 2006; Bollerslev et al. 2014). Hence, it is priced in asset returns.

With regard to the relation between the VRP and liquidity, the literature documents an impact of the VRP on liquidity mainly via two economic channels: investor risk aversion and macroeconomic uncertainty. On the one hand, Vayanos and Wang (2012) argue that investor risk aversion and asset return volatility exhibit negative impact on asset liquidity, whereas on the other, Segal et al. (2015) identify positive and negative innovations to macroeconomic growth as good and bad macroeconomic uncertainties, which not only display opposite effects on economic growth and asset prices but also correlate with subsequent stock liquidity. Empirically, Chiu (2020) and Chung and Chuwonganant (2014) show that uncertainty is an essential determinant of stock liquidity.

Motivated by these strands of the literature, in this paper we focus on the relations between the VRP, stock returns, and liquidity. In particular, we are interested in exploring the direct impact of the VRP on asset returns and liquidity, and the causal relation between stock returns and liquidity. To address these research questions, we adopt the Toda-Yamamoto Granger non-causality test (Toda and Yamamoto 1995) with tri-variate and bivariate vector autoregressions (VAR). This non-causality test provides valid statistics irrespective of whether the time series are integrated or co-integrated. Moreover, it allows variables to be employed in their levels, avoiding 
potential information loss due to data differencing (Alexander 2001; De Prado 2018). Hence, performing the Granger non-causality test in the VAR facilitates the analysis of the relation between variables, especially when they exhibit time dependency. Our data are monthly US data on the VRP, stock market returns, and the popular Amihud (2002) illiquidity measure over the period from January 1990 to December 2018.

The contributions of our paper are twofold. First, to the best of our knowledge, this is the first study that comprehensively examines the relations between the VRP, stock returns, and liquidity. Consistent with evidence in Statman et al. (2006) and Chordia et al. (2007), we show that stock market returns Granger-cause market (il)liquidity, while there is no causal relationship running from (il)liquidity to returns. This is further substantiated by the generalized impulse response function, which offers no evidence that stock market returns respond to changes in market illiquidity. Our results suggest that the research seeking to exploit the potential impact of liquidity on return prediction is unlikely to be successful; or it could be potentially contaminated by endogeneity between liquidity and returns, i.e., the reverse causality.

In terms of the causal relationship between the VRP and market liquidity, our results show that the VRP Granger-causes both stock returns and illiquidity, whereas there is little evidence that illiquidity Granger-causes the VRP. We further investigate the predictability of the VRP and liquidity over stock returns with a large set of control variables. Our in- and out-of-sample forecasting regression results suggest that the VRP, rather than illiquidity, exhibits significant predictive power for returns, thus it contains useful forecasting information. Taken together, our results outline the following causal relation: movements in the VRP drive innovations in stock market returns, which give rise to changes in market liquidity. They also indicate that fundamentally it is the movement of investor risk aversion and economic uncertainty that drives changes in liquidity via its impact on innovations in stock returns.

We perform a range of robustness checks and find that our baseline results remain qualitatively the same when we use different VRP and returns measures, during different sub-sample periods, and in the presence of a large set of economic control variables. They are also robust when we divide the sample into pre- and postfinancial crisis periods, and when we implement the alternative liquidity measure of Liu (2006). Hence, our paper adds to the literature by providing solid and comprehensive support for the predictability of the VRP on both stock returns and liquidity.

Our second contribution is that we explore yet another channel through which the VRP impacts (il)liquidity. More specifically, we examine how the VRP and (il)liquidity are related to stock returns by looking at the relation between the VRP and systematic factors, including the Fama-French three factors and the 
momentum factor of Carhart (1997), and between systematic factors and (il)liquidity. The Toda-Yamamoto Granger non-causality test reveals that the VRP Granger-causes the market, value, and momentum factors, while market and momentum factors affect variations in (il)liquidity. Furthermore, market (il)liquidity does not cause movement in any factor. These confirm our conjecture that investor risk aversion and economic uncertainty, captured by the VRP, exhibit strong predictive power for both asset returns and illiquidity. They are relevant to traders and fund managers who want to construct profitable trading strategies, and to regulators seeking to improve stock market efficiency and market quality.

The rest of the paper proceeds as follows. Section 2 summarizes related literature on economic uncertainty, risk aversion, and liquidity, and relation between liquidity and stock returns. Section 3 discusses data and variables. In Section 4, we conduct empirical analyses on the relation between key variables and perform robustness checks. Section 5 examines the channels through which the relations between the variables take effect. Finally, Section 6 concludes.

\section{Related literature}

\subsection{Economic uncertainty, investor risk aversion, and liquidity}

As an early theoretical effort, Karady (1982) develops an asset pricing model to examine the relation among dynamic investor risk attitude, temporal risk aversion, and expected returns to liquid and illiquid stocks. It concludes that temporal risk aversion exhibits a marked impact on liquidity premium. More recently, Vayanos and Wang (2012) show that the level of asset liquidity is higher when investor risk aversion is low and asset return volatility decreases in a market with liquidity demanders and suppliers and in the presence of information asymmetry and imperfect competition.

Empirically, by decomposing the macroeconomic uncertainty into good and bad components which are respectively associated with positive and negative innovations to macroeconomic growth, Segal et al. (2015) posit that these two uncertainty types exhibit opposite impact on economic growth and asset prices. In a similar framework, Chiu (2020) documents that good (bad) macroeconomic uncertainty is positively (negatively) related to subsequent stock liquidity. Utilizing information in the options market, Chung and Chuwonganant (2014) show that market uncertainty displays a stronger impact on stock liquidity than the combined effect of other determinants of stock liquidity. In addition, the uncertainty elasticity of liquidity rises in the presence of regulatory change in the US market. These findings are in line with theoretical predictions in Brunnermeier and Pedersen (2009) that a higher level of market uncertainty weakens market makers' liquidity-provision capacity. 
In a parallel strand of the literature, the VRP, induced by consumption uncertainty of an economy, reflects investor risk aversion (Rosenberg and Engle 2002; Bollerslev et al. 2009), and can be expressed as a nonlinear function of or a proxy for the aggregate degree of risk aversion (Bakshi and Madan 2006; Bollerslev et al. 2009). As indicated in Drechsler and Yaron (2011), the VRP is particularly informative for unravelling the connections between uncertainty, dynamics of an economy, preferences, and asset prices. The paper demonstrates that the VRP is a useful proxy for agents' perception of uncertainty and the risk of influential shocks to the economic state vector and bears a close relation to the risk aversion of a representative agent. Assuming a stochastic volatility process for asset returns, Bollerslev et al. (2011) argue that the VRP is related to risk aversion within the standard intertemporal asset pricing framework. Using a cost-free production-based equilibrium model, Ruan and Zhang (2018) find a positive relation between VRP and risk aversion.

Based on these studies, we infer that by capturing investor risk aversion and/or macroeconomic uncertainty, the VRP impacts market returns and liquidity.

\subsection{The relation between stock returns and liquidity}

There exists a voluminous literature on the relation between liquidity and stock returns. Amihud and Mendelson (1986) adopt the bid-ask spread as a proxy for illiquidity and discover that expected stock returns are an increasing and concave function of illiquidity. Since then, alternative measures of liquidity have been proposed in the literature, such as the marginal cost of trading, dollar trading volume, and turnover ratio with consistent conclusions (Brennan and Subrahmanyam 1996).

A number of theories and empirical results suggest that liquidity has substantial predictive power for future returns at both firm and market levels (e.g., Jones 2002; Baker and Stein 2004; Li et al. 2014; Kalli and Studies 2019; Liu et al. 2020; Huang and Ho 2020). This predictability can be attributed to transaction cost due to adverse selection (e.g., Stoll 1978; Glosten and Milgrom 1985; Easley and O’Hara 1987; Grossman and Miller 1988). If transaction costs are high, investors discount risky assets at a higher rate and require higher expected returns. As a result, stocks are observed to have lower liquidity. Empirically, higher transaction costs, lower turnover, and higher illiquidity ratios are associated with higher future returns (Glosten and Milgrom 1985; Lesmond et al. 1999; Bekaert et al. 2007; Baradarannia and Peat 2013; Guo et al. 2017; Chen et al. 2018; Yildiz et al. 2020).

Meanwhile, there also exists empirical support for past returns and future illiquidity. Lakonishok and Smidt (1986) show that higher daily positive price movement leads to a higher level of liquidity for individual 
stocks. Similarly, Smirlock and Starks (1988) document that trading volume is caused by the variability of stock returns, and this relation tends to be stronger around earnings announcements. The results imply that the delivery of information to investors follows a sequential process as past returns provide information to improve volume forecasts. At the aggregate market level, Chordia et al. (2001) document that liquidity increases in recent down markets but decreases in recent up markets, as the latter attracts more investors and prompts changes in optimal portfolio compositions.

Chordia et al. (2002) employ the inventory model of Stoll (1978) and conjecture that liquidity is driven by the inventory holding cost, which arises from financing constraints and risk. This inventory cost theory offers a plausible explanation for the observed phenomenon of liquidity drying up in falling markets (Bernardo and Welch 2004; Hameed et al. 2010). Another explanation for the positive association between past returns and liquidity is the cost of participation. The participation model of Orosel (1998) assumes that sidelined investors do not invest in the stock market because of the participation costs such as trading and information costs. High stock market returns will induce these investors to increase their estimates of investment profitability and become more willing to participate. With a large sample of 46 countries, Griffin et al. (2007) find a positive relationship between past returns and future trading activity. Similarly, Bekaert et al. (2007) offer supportive evidence in emerging markets.

From a behavioural finance perspective, when irrational investors are excessively optimistic about the markets, they tend to trade more actively and boost liquidity. Conversely, over-pessimistic investors avoid trading and reduce market turnover. In both cases, stock prices eventually revert to fundamental values. Hence, behavioural theories imply that liquidity and future returns are negatively related (Jones 2002; Baker and Stein 2004; Grinblatt and Keloharju 2009; Daniel and Hirshleifer 2015).

Behavioural finance theories also provide plausible explanations for the association between past returns and liquidity. According to the disposition effect in Shefrin and Statman (1985), investors are reluctant to trade in down markets and wish to realize the gains in up markets. This implies that past returns affect investor trading activities and, in turn, impact liquidity. Odean (1998) draws upon the overconfidence theory and argues that high market gains (losses) can increase (reduce) investor overconfidence about the precision of their information and their ability to select stocks. It shows that overconfident investors tend to trade more frequently in the following period thus pushing up liquidity. Supportive empirical evidence at the market level is offered in Gervais and Odean (2001) and Statman et al. (2006). 
To sum up, the literature sees inconclusive evidence on the causal relation between stock returns and liquidity. And we are not aware of prior studies that directly examine the impact of the VRP on liquidity.

\section{Data and variables}

\subsection{The variance risk premium (VRP)}

Following Bollerslev et al. (2009), Drechsler and Yaron (2011), and Carr and Wu (2009), we define the VRP as the difference between risk-neutral and physical expected variances as follows:

$$
V R P_{t}=E_{t}^{Q}\left(\operatorname{Var}_{t, t+1}\right)-E_{t}^{P}\left(\operatorname{Var}_{t, t+1}\right)
$$

where $Q$ and $P$ represent the risk-neutral and physical probability measures, respectively, and $E(\cdot)$ is the expectation operator. We follow the literature and employ the VIX index constructed via the model-free implied volatility approach as the measure of $E_{t}^{Q}\left(\operatorname{Var}_{t, t+1}\right)$ observed at time $t$ (Britten-Jones and Neuberger, 2000; Jiang and Tian, 2005).

The literature, however, disagrees on the proxy for expected realized volatility. For instance, Bollerslev et al. (2009) use the ex post realized return variation over the time interval $[t-1, t]$, which is the lagged realized variance over $[t, t+1]$. The method is valid under the assumption that realized volatility is a martingale process. Following the usual practice in the variance swap market, Carr and $\mathrm{Wu}$ (2009) use ex post forward realized variance from daily price as the measure of expected realized variance. Drechsler and Yaron (2011), however, argue that intraday S\&P 500 cash index returns may be subject to autocorrelation when summing up 500 individual stock prices. Hence, they consider the high frequency S\&P 500 futures realized variance forecasts, by projecting such variance on VIX and lagged index realized variance.

Due to the advantages and disadvantages of the aforementioned measures, we construct all three VRP measures following Bollerslev et al. (2009), Carr and Wu (2009), and Drechsler and Yaron (2011) for the expected realized volatility. The VRP thus obtained are denoted by $V R P^{B T Z}, V R P^{C W}$, and $V R P^{D Y}$, respectively.

\subsection{Illiquidity}

In our paper, we employ the illiquidity ratio of Amihud (2002) based on daily trading volumes and asset returns as the main liquidity measure. It is defined as the average ratio of absolute stock returns to the trading volume in dollars on the same day. The illiquidity ratio (ILLIQ) for stock $i$ in month $t$ is as follows: 


$$
I L L I Q_{i t}=\frac{1}{D_{i t}} \sum_{d=1}^{D_{i t}} \frac{\left|R_{i t d}\right|}{V O L D_{i t d}}
$$

where $R_{i, d}$ is the return on stock $i$ on day $d$ in month $t, V O L D_{i, d}$ is the corresponding daily volume in US dollars, and $D_{i}$ is the number of days with data available for stock $i$ in month $t$. The market illiquidity ratio is then calculated as the equally-weighted average of the Amihud (2002) illiquidity ratio of individual stocks over all sample stocks in the market. This widely used illiquidity measure outperforms other illiquidity proxies as it captures Kyle's lambda and has the largest correlation with liquidity benchmarks (Goyenko et al. 2009; Marshall et al. 2012; Mazouz et al. 2014; Wang and Zhang 2015; Saad and Samet 2017; Chong et al. 2017). Following Oded (2009) and Ascioglu et al. (2012), we scale the market illiquidity ratio by multiplying by $10^{6}$ and then take the natural logarithm in our analysis.

\subsection{Sample and descriptive statistics}

For our empirical analysis, we employ monthly observations of the VRP, illiquidity, and excess returns for the US market over the period from January 1990 to December 2018. In addition to the full sample, we also perform a robustness check for four sub-samples: 1990 to 2012, 1992 to 2014, 1994 to 2016 and 1996 to 2018 , which are equal in length and contain the 2008 global financial crisis.

First, we obtain $V R P^{B T Z}, V R P^{C W}$ and $V R P^{D Y}$ measures from Hao Zhou's website. ${ }^{1}$ The 5-minute log returns of the S\&P 500 index are employed to construct the monthly realised volatility, and the de-annualized monthlyend VIX-squared are used as a proxy for model-free implied volatility.

Second, we consider illiquidity for the S\&P 500 index and aggregate stock market (NYSE), respectively. We obtain daily returns, prices, and stock trading volumes from the CRSP. Based on Eq. (2), we construct the monthly market-wide illiquidity ratio for the NYSE (ILLIQ $\left.{ }^{N Y S E}\right)$ and the S\&P 500 index $\left(I L L I Q^{S P 500}\right)$.

Third, we also consider two stock return measures: the monthly excess returns on a value-weighted market portfolio (denoted by $V W$ ), and the S\&P 500 index excess return (denoted by INDEX). We download the monthly value-weighted returns, the S\&P 500 index returns, and the risk-free rate from the Center for Research in Security Prices (CRSP). We obtain the monthly Fama-French factors $\left(R_{m}-R_{f}, S M B\right.$, and $\left.H M L\right)$ and the momentum factor $(M O M)$ from Kenneth French's website. ${ }^{2}$

\footnotetext{
${ }^{1}$ Please see https://sites.google.com/site/haozhouspersonalhomepage/ for Hao Zhou's website.

${ }^{2}$ For Kenneth French's website, please see http://mba.tuck.dartmouth.edu/pages/faculty/ken.french/.
} 
Finally, following Bollerslev et al. (2009), our analysis also considers a number of economic predictors, including the price-earnings ratio ( $P E$, defined as the difference between the log value of prices and earnings); the price-dividend ratio ( $P D$, defined as the difference between $\log$ prices and $\log$ of dividends); the default spread (DFSP, defined as the difference between Moody's BAA- and AAA- rated corporate bond yields); the term spread (TMSP, defined as the difference between the 10-year T-bond and the 3-month T-bill yields); the stochastically de-trended risk-free rate (RREL, defined as the one-month T-bill rate minus its backward 12month moving averages); and the consumption-wealth ratio ( $C A Y$, defined as the deviations from the common trend in consumption, asset wealth, and labor income in Lettau and Ludvigson, 2001) ${ }^{3}$. The monthly $P E$ and $P D$ ratios for the S\&P 500 are obtained from Standard \& Poor's. The quarterly $C A Y$ is downloaded from Lettau and Ludvigson's website, and we linearly interpolate the quarterly values of $C A Y$ to obtain the monthly $C A Y$. The frequency of other economic data, the default spread, the term spread, the stochastically de-trended risk-free rate, is monthly, and they are downloaded from the Federal Reserve Bank of St. Louis website.

Table 1 reports the summary statistics for all variables: market returns ( $V W$ and INDEX), the VRP (VRP $P^{B T Z}$, $V R P^{C W}$ and $\left.V R P^{D Y}\right)$, Amihud illiquidity ratio $\left(I L L I Q^{N Y S E}\right.$ and $\left.I L L I Q^{S P 500}\right)$, and economic variables $(P D, P E$, DFSP, TMSP, RREL and CAY). All variables are reported as percentages where appropriate. We note that the annualized aggregate stock market returns are $6.76 \%$ and $6.89 \%$, respectively, for $V W$ and INDEX, while the standard deviations are $50.74 \%$ and $49.24 \%$. For the VRP measures, the mean values of $V R P^{B T Z}, V R P^{C W}$ and $V R P^{D Y}$ are $15.80,15.77$ and 15.86 , respectively, while their standard deviations are 20.19, 30.09 and 20.41 , respectively. This indicates that, compared to $V R P^{B T Z}$ and $V R P^{D Y}$, the measure of $V R P^{C W}$ is more volatile. Table 1 also illustrates that the illiquidity of the aggregate stock market is higher in mean but lower in standard deviation than for those of the S\&P 500 index.

\section{[Insert Table 1 around here]}

Furthermore, both return series display higher kurtosis than the normal distribution. Finally, we report the Ljung-Box Q-statistics for testing the autocorrelation of the variables. The Q-statistics are statistically significant for all variables except the excess returns. This is consistent with the results in Durand et al. (2011).

In Table 2 we provide the correlation matrix for the variables employed in this study. A high correlation is present between the illiquidity of the NYSE and S\&P 500 index, and between the two portfolio return measures. These imply that the measures are representative, consistent and can be substituted for one another. We also find

\footnotetext{
${ }^{3}$ Please see Lettau and Ludvigson (2001) for details of computing the deviations from the common trend in consumption, asset wealth, and labor income.
} 
that the illiquidity of neither the NYSE nor S\&P 500 is significantly related to contemporaneous portfolio returns. For the VRP, $V R P^{B T Z}, V R P^{C W}$, and $V R P^{D Y}$ positively correlate with contemporaneous illiquidity.

[Insert Table 2 around here]

\section{Empirical analyses}

\subsection{The Toda-Yamamoto Granger non-causality test}

We apply the Toda-Yamamoto Granger non-causality test to analyze the causal relationship between the VRP, returns and illiquidity. ${ }^{4}$ Following Chen et al. (2009), we test the causal relationship between the VRP and excess returns via the tri-variate vector autoregression (VAR) models using the asymmetric VAR equations below $^{5}$, which do not impose common lags across all variables:

$$
\begin{gathered}
E R_{t}=\alpha_{1}+\sum_{i=1}^{k_{1}} \beta_{1 i} E R_{t-i}+\sum_{i=1}^{k_{2}} \lambda_{1 i} V R P_{t-i}+\sum_{i=1}^{k_{3}} \varphi_{1 i} I L L I Q_{t-i}+\varepsilon_{1 t} \\
V R P_{t}=\alpha_{2}+\sum_{i=1}^{k_{4}} \beta_{2 i} E R_{t-i}+\sum_{i=1}^{k_{5}} \lambda_{2 i} V R P_{t-i}+\sum_{i=1}^{k_{6}} \varphi_{2 i} I L L I Q_{t-i}+\varepsilon_{2 t} \\
I L L I Q_{t}=\alpha_{3}+\sum_{i=1}^{k_{7}} \beta_{3 i} E R_{t-i}+\sum_{i=1}^{k_{8}} \lambda_{3 i} V R P_{t-i}+\sum_{i=1}^{k_{9}} \varphi_{3 i} I L L I Q_{t-i}+\varepsilon_{3 t}
\end{gathered}
$$

which allows us to explore the effect of each variable in predicting the others in the system and identify possible ordering issues. $E R$ and $V R P$ denote excess market returns ( $V W$ and INDEX) and the VRP $\left(V R P^{B T Z}, V R P^{C W}\right.$, and $\left.V R P^{D Y}\right)$, respectively, and the lag length of the VAR model, $k$, is chosen by optimizing the Akaike Information Criterion (AIC). ${ }^{6}$ Following Toda and Yamanoto (1995), we augment the correct VAR order, $k$, by the maximal order of integration, $d_{\max }$. The $\left(k+d_{\max }\right)$-th order of the VAR is then estimated and the Wald statistic for the null hypothesis of non-causality is obtained by imposing zero restriction on the first $p$ lags (Zapata and Rambaldi 1997). Consequently, the seemingly unrelated regression (SUR) is adopted to estimate the resulting system to

\footnotetext{
${ }^{4}$ For the full sample period and all sub-periods, the results of unit root tests show that all variables at level are stationary, i.e. I(0), except for the liquidity measures (ILLIQ $Q^{N Y S E}$ and $I L L I Q^{S P 500}$ ), which are integrated at order one, i.e. I(1). We used the augmented Dickey and Fuller (1981) ADF and Phillips and Perron (1988) PP models to test the null of a unit root against the alternative of stationarity, whereas the Kwiatkowski et al. (1992) KPSS tests the null of stationarity against the alternative of a unit root. Detailed results from the unit root tests are not reported here to conserve space but are available upon request from the authors.

${ }^{5}$ Asymmetric VAR means that the AVAR system has the same explanatory variables in each equation, but the explanatory variables can have different number of lags. Hence, it is more flexible in modeling dynamic systems.

${ }^{6}$ The maximal eigenvalues of the coefficient matrix of all the VAR models are smaller than 1, which suggests that all the VAR models are stable. Moreover, our VAR models show no serial correlation in the residuals.
} 
ensure efficiency (Chen et al. 2009). In other words, the Toda-Yamamoto Granger non-causality test is employed to ensure that the test statistic for Granger causality has standard asymptotic distribution for valid statistical inferences.

Tables 3 and 4 report the $p$-value of chi-square statistics for the Toda-Yamamoto Granger non-causality tests based on the tri-variate VAR models over the full sample without and with control variables, respectively. For the Granger-causality relationship between the VRP and stock market returns, there is compelling evidence in Table 3 that the VRP Granger-causes stock market returns, as the likelihood ratio statistics are consistently significant at the $1 \%$ level. Nevertheless, we cannot reject the null hypothesis that stock returns do not Grangercause the VRP. These results imply that the VRP drives stock market returns but not the other way round. With respect to the causal relationship between illiquidity and returns, there is insufficient evidence that illiquidity impacts on future stock returns. However, results indicate that illiquidity, both for the aggregate market and S\&P 500 index portfolios, is significantly Granger-caused by stock returns at the $1 \%$ level. Therefore, there exists uni-directional causality from returns to illiquidity, which is in line with the finding of Chordia et al. (2002)

\section{[Insert Table 3 around here]}

If variations in the VRP lead to changes in returns and, in turn, to movements in market liquidity, we expect to find evidence of impact from the VRP on stock liquidity. In particular, prior studies indicate that both investor risk aversion and economic uncertainty influence stock market liquidity (Vayanos and Wang 2012; Chung and Chuwonganant 2014; Chiu 2020). Table 3 further suggests that the VRP Granger-causes illiquidity but not the other way round. All the likelihood ratios are significant, except for the causal relation from $V R P^{B T Z}$ to illiquidity. In other words, we can reject the null hypothesis of no causality from the VRP to market liquidity but cannot reject the null hypothesis that illiquidity measures do not Granger-cause the VRP. Our results provide new evidence that the movements of market liquidity are driven by innovations of the VRP. The insignificant results of $V R P^{B T Z}$ may reflect Drechsler and Yaron (2011) argument of autocorrelation existing in the stable index when summing up 500 separate individual stock prices.

In sum, our baseline results in Table 3 provide preliminary evidence that market returns do not Grangercause the VRP, but the VRP does drive market returns. Second, returns Granger-cause illiquidity, while illiquidity does not affect market returns. Third, illiquidity does not Granger-cause the VRP, while there is 
substantial evidence that changes in the VRP Granger-cause movements in liquidity. These confirm our conjecture that variations in the VRP drive stock market returns and, in turn, market liquidity.

To examine whether the above relation is driven by other factors, we follow Bollerslev et al. (2009) and incorporate exogenous variables in the VAR models, including the price-earnings ratio, price-dividend ratio, default spread, term spread, stochastically de-trended risk-free rate, and consumption-wealth ratio as follows:

$$
\begin{aligned}
& E R_{t}=\alpha_{1}+\sum_{i=1}^{k_{1}} \beta_{1 i} E R_{t-i}+\sum_{i=1}^{k_{2}} \lambda_{1 i} V R P_{t-i}+\sum_{i=1}^{k_{3}} \varphi_{1 i} I L L I Q_{t-i}+P D_{t}+P E_{t}+D F S P_{t}+ \\
& T M S P R_{t}+R E L_{t}+C A Y_{t}+\varepsilon_{1 t} \\
& V R P_{t}=\alpha_{2}+\sum_{i=1}^{k_{4}} \beta_{2 i} E R_{t-i}+\sum_{i=1}^{k_{5}} \lambda_{2 i} V R P_{t-i}+\sum_{i=1}^{k_{6}} \varphi_{2 i} I L L I Q_{t-i}+P D_{t}+P E_{t}+D F S P_{t}+ \\
& T M S P R_{t}+R E L_{t}+C A Y_{t}+\varepsilon_{2 t} \\
& I L L I Q_{t}=\alpha_{3}+\sum_{i=1}^{k_{7}} \beta_{3 i} E R_{t-i}+\sum_{i=1}^{k_{8}} \lambda_{3 i} V R P_{t-i}+\sum_{i=1}^{k_{9}} \varphi_{3 i} I L L I Q_{t-i}+P D_{t}+P E_{t}+D F S P_{t}+ \\
& T M S P R_{t}+R E L_{t}+C A Y_{t}+\varepsilon_{3 t}
\end{aligned}
$$

The results, shown in Table 4, are in line with those presented in Table 3. Specifically, after controlling for economic variables, the VRP still Granger-causes returns and market illiquidity across different measures. Therefore, our baseline results of the causal relationship from the VRP to returns and illiquidity but not from returns and illiquidity to the VRP are not impacted by these economic variables.

\section{[Insert Table 4 around here]}

We further perform the analysis using the Toda-Yamamoto Granger non-causality test under the bi-variate VAR framework for a two-way relation using the following asymmetric VAR equations:

$$
\begin{gathered}
E R_{t}=\alpha_{1}+\sum_{i=1}^{k_{1}} \beta_{1 i} E R_{t-i}+\sum_{i=1}^{k_{2}} \lambda_{1 i} V R P_{t-i}+\varepsilon_{1 t} \\
V R P_{t}=\alpha_{2}+\sum_{i=1}^{k_{3}} \beta_{2 i} E R_{t-i}+\sum_{i=1}^{k_{4}} \lambda_{2 i} V R P_{t-i}+\varepsilon_{2 t}
\end{gathered}
$$

We examine whether the VRP Granger-causes excess returns and whether excess returns Granger-cause the VRP using equations (5a) - (5b). We also investigate the Ganger-causality relation between illiquidity and returns using equations (6a) - (6b) and between the VRP and illiquidity using (7a) - (7b).

$$
E R_{t}=\alpha_{1}+\sum_{i=1}^{k_{1}} \beta_{1 i} E R_{t-i}+\sum_{i=1}^{k_{2}} \lambda_{1 i} \operatorname{ILLIQ}_{t-i}+\varepsilon_{1 t}
$$




$$
\begin{gathered}
V R P_{t}=\alpha_{2}+\sum_{i=1}^{k_{3}} \beta_{2 i} E R_{t-i}+\sum_{i=1}^{k_{4}} \lambda_{2 i} \operatorname{ILLIQ}_{t-i}+\varepsilon_{2 t} \\
V R P_{t}=\alpha_{1}+\sum_{i=1}^{k_{1}} \beta_{1 i} V R P_{t-i}+\sum_{i=1}^{k_{2}} \lambda_{1 i} I L L I Q_{t-i}+\varepsilon_{1 t} \\
I L L I Q_{t}=\alpha_{2}+\sum_{i=1}^{k_{3}} \beta_{2 i} V R P_{t-i}+\sum_{i=1}^{k_{4}} \lambda_{2 i} I L L I Q_{t-i}+\varepsilon_{2 t}
\end{gathered}
$$

Tables 5 and 6 report the $p$-value of chi-square statistics for the Toda-Yamamoto Granger non-causality tests based on the bi-variate VAR models without and with control variables, respectively. In order to test the robustness of the results over different sample periods with sufficient observations, we conduct the test over four 23-year rolling windows: 1990-2012, 1992-2014, 1994-2016, and 1996-2018. We reach the same conclusions as those based on tri-variate VAR models: changes in the VRP drive innovations in stock returns and stock returns affect illiquidity. For the relation between illiquidity and the VRP, we find no evidence of illiquidity driving the VRP, while there is an evident causal relationship from the VRP to illiquidity in most cases. We also divide the entire sample period into pre- and post-financial crisis windows (1990-2006 and 2007-2018), and the results remain qualitatively the same. These results are available upon request.

\section{[Insert Tables $5 \& 6$ around here]}

Overall, the results from the Toda-Yamamoto Granger non-causality test with tri- and bi-variate VAR models provide strong evidence to suggest that investor risk aversion Granger-causes stock market returns, and in turn, affects illiquidity. This further supports the evidence that innovations in investor risk aversion cause variations in market returns (Bollerslev et al. 2009; Drechsler and Yaron 2011) and sheds light on the debate over causality between stock returns and liquidity. More importantly, our results concur with the arguments for the role played by aggregate risk aversion and economic uncertainty (Vayanos and Wang 2012; Chung and Chuwonganant 2014; Chiu 2020) by revealing new evidence on the direct relation between the VRP and stock market liquidity and that VRP exhibits strong predictability not only on stock returns but also on liquidity.

\subsection{The impulse response}

Following Koop et al. (1996) and Griffin et al. (2007), we utilize the generalized impulse response function derived from the VAR models to show how a variable responds to a shock on other variables in the 
system, and how long the impact will persist through the VAR. ${ }^{7}$ The generalized technique is superior to the traditional approach since it is not sensitive to the ordering of variables in the underlying VAR. Figure 1 depicts the estimated generalized impulse response functions for the VRP, excess returns, and illiquidity, with control variables for 24 months for the full sample. The response is depicted in a solid line with the confidence intervals (two standard errors) in dashed lines. In each graph, the horizontal axis represents the months relative to the shock, which occurs in Month 1. The vertical axis denotes the percentage change in each variable following a one-standard-deviation increase in the other variable.

\section{[Insert Figure 1 around here]}

In Panel A, we plot how stock returns respond to a one-standard-deviation innovation in the VRP and illiquidity. The third diagram in Panel A shows that stock returns significantly respond to shocks in the VRP. In response to a one-standard-deviation disturbance in $V R P^{B T Z}$, stock returns are initially negative; they begin to increase in the first month, reach $10 \%$ in the second month, and decline gradually from the fourth month. For the first six months, the impulse response function is positive and significant. This indicates that the shocks in $V R P^{B T Z}$ exhibit a positive effect on stock market returns. It also implies that it takes about seven months for the stock returns to recover from a shock to the VRP on stock returns, for the relation between the two variables to fully play out while other variables remain constant. Similar patterns of impulse response are shown for the other two VRP measures, $V R P^{C W}$ and $V R P^{D Y}$. In contrast, the last two diagrams illustrate that, although the response of returns to a shock in $I L L I Q^{N Y S E}$ and $I L L I Q^{S P S O 0}$ is initially significant, it becomes insignificant after the first month. This is consistent with our prior results that illiquidity measures for both aggregate stock market and S\&P 500 index do not Granger-cause returns. In addition, our results are qualitatively similar for returns to the S\&P 500 index in Panel B.

Panels C and D display how illiquidity responds to a shock to stock market returns or the VRP. We find that a one-standard-deviation disturbance to $V W$ and INDEX results in around a $0.2 \%$ decrease in stock illiquidity for the first two months, and gradually decreases. It is worth noting that the negative impact is significant for more than ten months following the shock, consistent with the findings from the Toda-Yamamoto Granger non-causality test indicating that changes in stock market returns lead to innovations in illiquidity. Meanwhile, a similar pattern is observed between illiquidity and the VRP. The marginally significant and negative response of illiquidity to $V R P^{B T Z}$ can be observed using conventional levels of confidence. Similarly,

\footnotetext{
${ }^{7}$ The number of lags is selected by a general-to-specific approach to satisfy the assumption of no serial correlation and the stationary condition of VAR models.
} 
the fourth figure in Panel $\mathrm{C}$ shows that a one-standard-deviation disturbance to $V R P^{C W}$ results in around $0.1 \%$ decrease in illiquidity for the NYSE stocks in the first two months. Panel D illustrates the results of illiquidity on the S\&P 500 index with similar patterns. Together, Panels C and D reveal that shocks in stock market returns have a substantial negative impact on illiquidity and so do shocks in VRP measures.

The impulse response of the VRP to illiquidity and market returns are shown in Panels E, F, and G. Although the initial responses of VRP measures to shocks in returns or illiquidity are significant for some measures, the significant effects disappear rapidly and last for at most two months. It is worth noting that the statistically significant responses of VRP measures to both excess returns and illiquidity cannot be observed. Therefore, it appears that shocks in neither stock market returns nor illiquidity affect investor attitudes on risk aversion, measured by the VRP. ${ }^{8}$

To summarize, the impulse response functions reveal a significant and positive response of stock returns to shocks in the VRP, a significant and negative response of illiquidity to shocks in stock returns, and a significant response of illiquidity to shocks in the VRP. These are consistent with theoretical predictions and empirical evidence in a number of prior studies that we discuss above in Section 2.

\subsection{The in-sample and out-sample forecasting}

We investigate the predictability of the VRP and illiquidity through in-sample regression as follows (Lettau and Ludvigson 2001; Ang and Bekaert 2007):

$$
R_{t+1}=\alpha+\beta \mathrm{x}_{t}+\varepsilon_{t+1}
$$

where $R_{\mathrm{t}+1}$ is the excess stock market return at time $t+1, x_{t}$ is the VRP or illiquidity at time $t$, and $\varepsilon_{t+1}$ is a zeromean disturbance term. The significance of $\beta$ is used to evaluate the in-sample forecasting of predictors over excess returns. Following Neely et al. (2014), we use a one-sided alternative hypothesis to enhance the statistical power and compute $p$-values with a wild bootstrap procedure to address the concern for coefficient bias (Stambaugh 1999). ${ }^{9}$

The first three columns in Panel A of Table 7 report the in-sample slope coefficients, the heteroscedasticity-robust $t$-statistics, and the $R^{2}$. The results indicate that for the three VRP proxies, the

\footnotetext{
${ }^{8}$ We have also conducted the impulse response functions with Cholesky decomposition and structural vector autoregression (SVAR) and obtained consistent results. These results are available upon request from the authors.

${ }^{9}$ Stambaugh (1999) shows that coefficients in predictive regressions such as those in Eq. (7) suffer from finite sample bias and the normal $t$-test could be misleading when the predictors are highly persistent.
} 
estimated $\beta$ for $V R P^{B T Z}$ and $V R P^{C W}$ is statistically significant at the $1 \%$ level, suggesting $V R P^{B T Z}$ and $V R P^{C W}$ can significantly predict future market returns in-sample. Meanwhile, the two stock market illiquidity measures do not exhibit significant return predictability for market returns. These findings are consistent with those in Tables 3-6 and provide corroborating evidence that the VRP, not illiquidity, Granger-causes stock returns.

\section{[Insert Table 7 around here]}

Following Campbell and Thompson (2008) and Welch and Goyal (2008), we also test the out-of-sample forecasting of VRP and illiquidity, respectively, via a recursive approach. We divide the whole sample into two sub-samples: initial estimation period from time 1 (1990:01) to time $n$ (1999:12) with the first $n$ monthly observations, and the out-of-sample forecast period from time $n+1$ (2000:01) to time $T(2018: 12)$ with the remaining $T-n$ observations. We compute the first out-of-sample forecast for time $n+1$ (2000:01) by estimating Eq. (7) using observations from 1 to $n$. We then expand the estimation window and obtain return forecasts for the following period. We repeat the above steps until we reach the end of our sample period. In this way we obtain a time series of predicted excess market returns $\left\{\hat{r}_{t+1}\right\}_{t=n}^{T-1}$.

We evaluate the out-of-sample forecasts using the out-of-sample $R^{2}$ os of Campbell and Thompson (2008) and the MSFE-adjusted statistics of Clark and West (2007). The $R^{2}$ os statistic is given below:

$$
R_{O S}^{2}=1-\frac{\sum_{k=1}^{q}\left(r_{n+k}-\hat{r}_{n+k}\right)^{2}}{\sum_{k=1}^{q}\left(r_{n+k}-\bar{r}_{n+k}\right)^{2}}
$$

where $r_{n+k}$ represents the actual monthly excess market return for $n+k, \hat{r}_{n+k}$ denotes the forecast based on Eq. (7) estimated over the period $n+k-1$, and $\bar{r}_{n+k}$ is the historical average benchmark estimated over the period $n+k-1$. The $R^{2}$ os measures the proportional reduction in mean squared forecasting errors (MSFE) between the predictive regression forecast and the historical average. If $R^{2} \mathrm{OS}$ is greater than zero, it indicates that forecasts based on predictive regression outperform historical average in MSFE. Campbell and Thompson (2008) suggest that a monthly $R^{2}$ os near $0.5 \%$ is economically significant. In addition, the MSFE-adjusted statistic in Clark and West (2007) is employed to test the null hypothesis that the historical average MSFE is less than or equal to the MSFE of the predictive regression forecast against the one-sided (upper-tail) alternative hypothesis that the historical average MSFE is greater than the predictive regression MSFE.

Columns (4) and (5) in Panel A Table 7 report the out-of-sample forecasting performance of the VRP and illiquidity, respectively. In column (4), we find that the $R^{2}$ os for $V R P^{B T Z}$ or $V R P^{C W}$ is higher than $0.5 \%$. However, the $R^{2}$ os for the two illiquidity measures are all negative. Furthermore, the MSFE-adjusted statistic in column (5) 
implies that the MSFE values of $V R P^{B T Z}$ or $V R P^{C W}$ are significantly less than the historical average MSFE, while the two illiquidity measures fail to outperform the benchmark. Similar results can be found in Columns (6) - (7) when using 1990:01-2004:12 as the initiation period and 2005:01-2018:12 as the forecast evaluation period. These results are in line with the in-sample findings and indicate that the VRP, but not liquidity, exhibits significant out-of-sample forecasting for market returns.

Finally, we use the principal component of 14 macro-economic factors proposed by Welch and Goyal (2008) as control variables and test the additional predictive power of the VRP and illiquidity. The results are reported in Panel B Table 7. They show that the coefficients of $V R P^{B T Z}$ and $V R P^{C W}$ remain statistically significant at the $1 \%$ level after controlling for the principal component of 14 macroeconomic variables. It is worth noting that when either $V R P^{B T Z}$ or $V R P^{C W}$ is added to the regression, the $R^{2}$ increases massively compared with the baseline model with the principle component of macroeconomic variables. In contrast, the two liquidity measures do not exhibit forecasting power for excess market returns.

\subsection{Alternative liquidity measure}

To further strengthen the validity of our results and capture other dimensions of liquidity, we consider an alternative measure of liquidity proposed by Liu (2006), which captures multidimensional dimensions of liquidity, including trading quantity, trading speed, and trading cost (spread). It is defined as the standardized turnover-adjusted number of zero daily trading volumes over the previous twelve months. This liquidity measure for each stock in each year is computed using the following equation:

$$
L M=\left[\text { NoVol }+\frac{1 / 12 \_ \text {months turnover }}{\text { Deflator }}\right] \times \frac{21 \times 12}{\text { NoTD }}
$$

where $\mathrm{NoVol}$ is the number of zero daily volumes over the previous twelve months, 12_month turnover is the sum of daily turnover over the previous twelve months, daily turnover being the ratio of the number of shares traded to the number of shares outstanding. NoTD denotes the total number of trading days in the market over the previous twelve months. Deflactor is chosen such that Eq. (10) holds for all sample stocks:

$$
0<\frac{1 / 12 \_ \text {months turnover }}{\text { Deflator }}<1
$$

The turnover adjustment (the second term in the brackets) distinguishes two stocks with the same integer number of zero daily trading volumes. Following Liu (2006), we multiply $21 \times 12 /$ NoTD in order to standardize the number of trading days in a month to 21 and make the liquidity measure comparable over time. We then 
calculate the LM of the market by taking the equally-weighted average LM of all the sample stocks in the market.

We conduct the Toda-Yamamoto Granger non-causality tests with the application of tri-variate vector autoregression (VAR) models for the relationship between the VRP, stock market returns, and liquidity with conventional economic controls using Liu (2006) liquidity measure. The results, reported in Table 8, are consistent with those in Table 4, in which we use Amihud (2002) illiquidity ratio. More specifically, we still find one-way causal relationship running from stock returns to liquidity and from the VRP to liquidity when we use the alternative liquidity measure. These results further support our conjecture that variation in the VRP can lead to changes in stock returns and, in turn, to movements in liquidity.

[Insert Table 8 around here]

\section{The channels of the VRP effect}

Having established the relation between the VRP, stock returns, and illiquidity, we are interested in further determining the channels through which the relation takes effect. Following the findings in Tables 3-6, we infer that the VRP Granger-causes stock returns via certain factors and, in turn, illiquidity, and the factors also affect stock illiquidity. Given the evidence in the asset pricing literature (Fama and French 1992, 1993, 1995), we take the Fama-French three factors, i.e. market factor $\left(R_{m}-R_{f}\right)$, size factor $(S M B)$, and value factor $(H M L)$, along with the momentum factor $(M O M)$, as candidates.

To implement the investigation, we again apply the Toda-Yamamoto Granger non-causality test between the VRP (illiquidity) and the four factors $\left(R_{m}-R_{f}, S M B, H M L\right.$, and $\left.M O M\right)$. We summarize the results in Table 9. Panel A shows that changes in the VRP Granger-cause the variation in market factor, value factor, and momentum factor, but not size factor, for the full sample period and all sub-sample periods. More specifically, the likelihood ratio test statistics for the null hypothesis that the VRP does not Granger-cause the market factor is statistically significant for all cases. Similarly, the null hypothesis of Granger non-causality is rejected for the value factor and momentum factor in all samples, whereas the null is rejected in seven out of twelve cases for the size factor. Meanwhile, there is limited evidence to reject the null hypothesis that the four factors do not cause the VRP as most of the likelihood ratio test statistics are insignificant.

[Insert Table 9 around here] 
Panel B demonstrates a uni-directional causal relationship from the market and momentum factors to illiquidity, but the evidence is unclear for the relation between illiquidity and size and value factors. Only about half of the results are significant at the $5 \%$ level for the causal relationship running from illiquidity to the size factor and from illiquidity to the value factor. Taken together, the evidence in Table 9 shows that variations in the VRP drive changes in liquidity via market and momentum factors. Importantly and consistent with baseline results, there is no clear evidence suggesting uni-directional causality from illiquidity to any of the factors.

For robustness, Table 10 reports the results for the same Granger non-causality test when additional economic variables - PE ratio, $\mathrm{PD}$ ratio, default spread, term spread, stochastically de-trended risk-free rate, and CAY - are included. The results are similar to those reported in Table 9, wherein the VRP Granger-causes market and momentum factors, and in turn affects stock returns and illiquidity. This indicates that the VRP influences stock returns and liquidity via time-varying market and momentum factors. The results show that illiquidity does not Granger-cause any of the factors, and does not affect stock returns.

[Insert Table 10 around here]

\section{Conclusion}

In the literature, the VRP - considered an indicator capturing investor risk aversion and aggregate economic uncertainty - and liquidity are both useful variables for explaining innovations in stock returns. However, the causal relation between liquidity and stock returns is still being debated, and investigations into the causal relationship between VRP and liquidity remain limited.

This study contributes to the literature by providing comprehensive evidence that fills these gaps. We examine relationships among the VRP, stock returns and liquidity using US monthly data from January 1992 to December 2018. We find that the VRP Granger-causes stock returns and stock returns Granger-cause (il)liquidity. This causal relation does not hold the other way around. Our results are robust for the whole sample and different sub-sample periods, with different VRP, returns and (il)liquidity measures, and in the presence of control variables. They are also robust when we divide the sample into pre- and post-financial crisis periods, as well as when we employ the alternative liquidity measure of Liu (2006). Our impulse response graphs provide corroborating evidence. They demonstrate that stock returns significantly and positively respond to shocks in the VRP; that stock (il)liquidity significantly and negatively responds to shocks in both stock returns and the VRP; and that stock returns and illiquidity do not affect the variance risk premium. 
We further examine the forecasting power of the VRP and (il)liquidity on returns. It is apparent that investor risk aversion and economic uncertainty, proxied by the VRP, exhibit strong forecasting power for future excess returns both in-sample and out-of-sample.

Finally, we show that changes in the VRP drive variations in the market, value, and momentum factors. There also exists a causal relation from market and momentum factors to stock (il)liquidity. However, no supporting evidence is available for a causal relation from the four factors to the VRP or from (il)liquidity to these factors. The implication is that the VRP mainly drives stock returns and (il)liquidity via time-varying market and momentum factors. 


\section{References}

Alexander C (2001) Market Models: A Guide to Financial Data Analysis, 1st edn. John Wiley \& Sons, Chichester

Amihud Y (2002) Illiquidity and stock returns: Cross-section and time-series effects. J Financ Mark 5:31-56

Amihud Y, Mendelson H (1986) Asset pricing and the bid-ask spread. J Financ Econ 17:223-249

Ang A, Bekaert G (2007) Stock return predictability: Is it there? Rev Financ Stud 20:651-707

Ascioglu A, Hegde SP, Krishnan G V., McDermott JB (2012) Earnings management and market liquidity. Rev Quant Financ Account 38:257-274

Baker M, Stein JC (2004) Market liquidity as a sentiment indicator. J Financ Mark 7:271-299

Bakshi G, Madan D (2006) A theory of volatility spreads. Manage Sci 52:1945-1956

Baradarannia MR, Peat M (2013) Liquidity and expected returns-Evidence from 1926-2008. Int Rev Financ Anal 29:10-23

Bekaert G, Harvey CR, Lundblad C (2007) Liquidity and expected returns: Lessons from emerging markets. Rev Financ Stud 20:1783-1831

Bernardo AE, Welch I (2004) Liquidity and financial market runs. Q J Econ 119:135-158

Bollerslev T, Gibson M, Zhou H (2011) Dynamic estimation of volatility risk premia and investor risk aversion from option-implied and realized volatilities. J Econom 160:235-245

Bollerslev T, Marrone J, Xu L, Zhou H (2014) Stock return predictability and variance risk premia: Statistical inference and international evidence. J Financ Quant Anal 49:633-661

Bollerslev T, Tauchen G, Zhou H (2009) Expected stock returns and variance risk premia. Rev Financ Stud 22:4463-4492

Brennan MJ, Subrahmanyam A (1996) Market microstructure and asset pricing: On the compensation for illiquidity in stock returns. J Financ Econ 41:441-464

Brunnermeier MK, Pedersen LH (2009) Market liquidity and funding liquidity. Rev Financ Stud 22:2201-2238

Campbell JY, Thompson SB (2008) Predicting excess stock returns out of sample: Can anything beat the historical average? Rev Financ Stud 21:1509-1531

Carr P, Wu L (2009) Variance risk premiums. Rev Financ Stud 22:1311-1341

Chen AS, Cheng LY, Cheng KF (2009) Intrinsic bubbles and granger causality in the S\&P 500: Evidence from long-term data. J Bank Financ 33:2275-2281

Chen Y, Eaton GW, Paye BS (2018) Micro(structure) before macro? The predictive power of aggregate illiquidity for stock returns and economic activity. J Financ Econ 130:48-73

Chiu YC (2020) Macroeconomic uncertainty, information competition, and liquidity. Financ Res Lett $34: 101262$

Chong TTL, Tsui SC, Chan WH (2017) Factor pricing in commodity futures and the role of liquidity. Quant Financ 17:1745-1757

Chordia T, Huh S-W, Subrahmanyam A (2007) The cross-section of expected trading activity. Rev Financ Stud 20:709-740

Chordia T, Roll R, Subrahmanyam A (2001) Market liquidity and trading activity. J Finance 56:501-530

Chordia T, Roll R, Subrahmanyam A (2002) Order imbalance, liquidity, and market returns. J Financ Econ 65:111-130

Chung KH, Chuwonganant C (2014) Uncertainty, market structure, and liquidity. J Financ Econ 113:476-499

Clark TE, West KD (2007) Approximately normal tests for equal predictive accuracy in nested models. J Econom 138:291-311

Daniel K, Hirshleifer D (2015) Overconfident investors, predictable returns, and excessive trading. J Econ Perspect 29:61-88

De Prado ML (2018) The 10 reasons most machine learning funds fail. J Portf Manag 44:120-133

Dickey DA, Fuller WA (1981) Likelihood ratio statistics for autoregressive time series with a unit root. 
Econometrica 49:1057-1072

Drechsler I, Yaron A (2011) What's vol got to do with it. Rev Financ Stud 24:1-45

Durand RB, Lim D, Zumwalt JK (2011) Fear and the fama-french factors. Financ Manag 40:409-426

Easley D, O'Hara M (1987) Price, trade size, and information in securities markets. J Financ Econ 19:69-90

Fama EF, French KR (1992) The cross-section of expected stock returns. J Finance 47:427-465

Fama EF, French KR (1993) Common risk factors in the returns on stocks and bonds. J Financ Econ 33:3-56

Fama EF, French KR (1995) Size and Book-to-Market Factors in Earnings and Returns. J Finance 50:131-155

Feunou B, Jahan-Parvar MR, Okou C (2018) Downside variance risk premium. J Financ Econom 16:341-383

Gallant AR, Rossi PE, Tauchen G (1992) Stock prices and volume. Rev Financ Stud 5:199-242

Gervais S, Odean T (2001) Learning to be overconfident. Rev Financ Stud 14:1-27

Glosten LR, Milgrom PR (1985) Bid, ask and transaction prices in a specialist market with heterogeneously informed traders. J Financ Econ 14:71-100

Goyenko RY, Holden CW, Trzcinka CA (2009) Do liquidity measures measure liquidity? J Financ Econ 92:153-181

Griffin JM, Nardari F, Stulz RM (2007) Do investors trade more when stocks have performed well? Evidence from 46 countries. Rev Financ Stud 20:905-951

Grinblatt M, Keloharju M (2009) Sensation seeking, overconfidence, and trading activity. J Finance 64:549-578

Grossman SJ, Miller MH (1988) Liquidity and Market Structure. J Finance 43:617-633

Guo H, Mortal S, Savickas R, Wood R (2017) Market illiquidity and conditional equity premium. Financ Manag 46:743-766

Hameed A, Kang W, Viswanathan S (2010) Stock market declines and liquidity. J Finance 65:257-293

Hiemstra C, Jones J (1994) Testing for linear and nonlinear granger causality in the stock price-volume relation. J Finance 49:1639-1664

Hollstein F, Simen CW (2020) Variance risk: A bird's eye view. J Econom 215:517-535

Huang HY, Ho KC (2020) Liquidity, earnings management, and stock expected returns. North Am J Econ Financ 54:101261

Jones CM (2002) A century of stock market liquidity and trading costs. SSRN Electron J https://ssrn.com/abstract=313681

Kalli M, Studies ME (2019) Stock market liquidity and return predictability: A bayesian nonparametric approach. Rev Financ Stud In press.

Karady G (1982) The effect of temporal risk aversion on liquidity preference. J Financ Econ 10:467-483

Koop G, Pesaran MH, Potter SM (1996) Impulse response analysis in nonlinear multivariate models. J Econom 74:119-147

Kwiatkowski D, Phillips PCB, Schmidt P, Shin Y (1992) Testing the null hypothesis of stationarity against the alternative of a unit root. How sure are we that economic time series have a unit root? J Econom 54:159178

Lakonishok J, Smidt S (1986) Volume for winners and losers: Taxation and other motives for stock trading. J Finance 41:951-974

Lesmond DA, Ogden JP, Trzcinka CA (1999) A new estimate of transaction costs. Rev Financ Stud 12:11131141

Lettau M, Ludvigson S (2001) Consumption, aggregate wealth, and expected stock returns. J Finance 56:815849

Li G, Lu L, Wu B, Zhang Z (2014) Asymmetric information, illiquidity and asset returns: Evidence from China. Quant Financ 14:947-957

Liu G, Gregoriou A, Bo Y (2020) How do markets value stock liquidity? Comparative evidence from the UK, the US, Germany and China. Econ Lett 186:108500

Liu W (2006) A liquidity-augmented capital asset pricing model. J Financ Econ 82:631-671

Marshall BR, Nguyen NH, Visaltanachoti N (2012) Commodity liquidity measurement and transaction costs. Rev Financ Stud 25:599-638

Mazouz K, Daya W, Yin S (2014) Index revisions, systematic liquidity risk and the cost of equity capital. J Int Financ Mark Institutions Money 33:283-298

Merton RC (1973) An intertemporal capital asset pricing model. Econometrica 41:867

Neely CJ, Rapach DE, Tu J, Zhou G (2014) Forecasting the equity risk premium: The role of technical indicators. Manage Sci 60:1772-1791

Odean T (1998) Volume, volatility, price, and profit when all traders are above average. J Finance 53:18871934

Oded J (2009) Optimal execution of open-market stock repurchase programs. J Financ Mark 12:832-869

Orosel GO (1998) Participation costs, trend chasing, and volatility of stock prices. Rev Financ Stud 11:521-557

Pástor L', Stambaugh RF (2003) Liquidity risk and expected stock returns. J Polit Econ 111:642-685

Phillips PCB, Perron P (1988) Testing for a unit root in time series regression. Biometrika 75:335-346 
Rosenberg J V., Engle RF (2002) Empirical pricing kernels. J Financ Econ 64:341-372

Ruan X, Zhang JE (2018) Equilibrium variance risk premium in a cost-free production economy. J Econ Dyn Control 96:42-60

Saad M, Samet A (2017) Liquidity and the implied cost of equity capital. J Int Financ Mark Institutions Money $51: 15-38$

Segal G, Shaliastovich I, Yaron A (2015) Good and bad uncertainty: Macroeconomic and financial market implications. J Financ Econ 117:369-397

Shefrin H, Statman M (1985) The disposition to sell winners too early and ride losers too lLong: Theory and evidence. J Finance 40:777-790

Smirlock M, Starks L (1988) An empirical analysis of the stock price-volume relationship. J Bank Financ $12: 31-41$

Stambaugh RF (1999) Predictive regressions. J Financ Econ 54:375-421

Statman M, Thorley S, Vorkink K (2006) Investor overconfidence and trading volume. Rev Financ Stud 19:1531-1565

Stoll HR (1978) The supply of dealer services in securities markets. J Finance 33:1133-1151

Toda HY, Yamamoto T (1995) Statistical inference in vector autoregressions with possibly integrated processes. J Econom 66:225-250

Vayanos D, Wang J (2012) Liquidity and asset returns Under asymmetric information and imperfect competition. Rev Financ Stud 25:1339-1365

Wang Q, Zhang J (2015) Individual investor trading and stock liquidity. Rev Quant Financ Account 45:485-508

Welch I, Goyal A (2008) A comprehensive look at the empirical performance of equity premium prediction. Rev Financ Stud 21:1455-1508

Yildiz S, Van Ness B, Van Ness R (2020) VPIN, liquidity, and return volatility in the U.S. equity markets. Glob Financ J 45:100479

Zapata HO, Rambaldi AN (1997) Monte carlo evidence on cointegration and causation. Oxf Bull Econ Stat 59:285-298 
Table 1. Descriptive statistics

\begin{tabular}{|c|c|c|c|c|c|c|c|c|c|c|c|c|c|}
\hline & $\bar{~} \overline{V W}$ & INDEX & $\bar{l} V R P^{B T Z}$ & 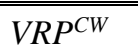 & $\bar{V} V R P^{D Y}$ & ILLIQ $Q^{N Y S E}$ & ILLIQ ${ }^{S P 500}$ & $P D$ & $P E$ & $\overline{D D F S P}$ & 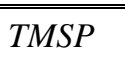 & $\overline{\text { RREL }}$ & CAY \\
\hline Mean & 6.76 & 6.89 & 15.80 & 15.77 & 15.86 & -2.66 & -7.62 & 3.11 & 3.91 & 0.95 & 1.86 & -0.13 & -0.16 \\
\hline Median & 12.19 & 11.48 & 12.85 & 12.97 & 10.93 & -2.99 & -8.00 & 3.07 & 3.93 & 0.87 & 1.88 & -0.01 & -0.27 \\
\hline Maximum & 135.08 & 132.55 & 115.85 & 109.98 & 201.42 & 1.28 & -3.76 & 4.82 & 4.50 & 3.38 & 3.76 & 1.86 & 3.26 \\
\hline Minimum & -223.55 & -203.53 & -218.56 & -388.17 & -48.04 & -4.71 & -9.69 & 2.60 & 3.25 & 0.55 & -0.53 & -2.51 & -4.72 \\
\hline Std. Dev. & 50.74 & 49.24 & 20.19 & 30.09 & 20.41 & 1.47 & 1.54 & 0.35 & 0.27 & 0.39 & 1.07 & 0.79 & 2.03 \\
\hline Skewness & -0.73 & -0.61 & -3.64 & -6.93 & 3.63 & 0.51 & 0.50 & 2.16 & -0.17 & 3.19 & -0.12 & -0.76 & -0.26 \\
\hline Kurtosis & 4.54 & 4.26 & 56.24 & 96.23 & 27.80 & 2.19 & 2.11 & 9.96 & 2.73 & 16.97 & 2.08 & 3.71 & 2.32 \\
\hline Observations & 348 & 348 & 348 & 348 & 348 & 348 & 348 & 348 & 348 & 348 & 348 & 348 & 348 \\
\hline \multicolumn{14}{|c|}{ Autocorrelation } \\
\hline Q-stat (1 lag) & 2.04 & 0.50 & 27.84 & 26.85 & 23.59 & 341.29 & 343.21 & 336.13 & 341.75 & 326.04 & 332.32 & 316.72 & 328.91 \\
\hline$p$-value & 0.15 & 0.48 & 0.00 & 0.00 & 0.00 & 0.00 & 0.00 & 0.00 & 0.00 & 0.00 & 0.00 & 0.00 & 0.00 \\
\hline
\end{tabular}

$\overline{\text { The table shows the summary statistics of all variables used in this study. The variables are liquidity measures }\left(I L L I Q^{N Y S E} \text { and } I L L I Q^{S P 500}\right) \text {, the variance risk premium (VRPBTZ }}$ $V R P^{C W}$ and $V R P^{D Y}$ ), return series $(V W$ and INDEX) and control variables (PD, PE, DFSP, TMSP, RREL and CAY). Following Bollerslev et al. (2009), all variables are reported in annualized percentage form whenever appropriate. The analysis uses monthly data from January 1990 to December 2018. 
Table 2. Correlation matrix

\begin{tabular}{|c|c|c|c|c|c|c|c|c|c|c|c|c|c|}
\hline & 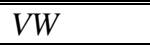 & IINDEX & $\bar{V} V R P^{B T Z}$ & $\frac{e^{\prime} V R P^{C W}}{4}$ & $\bar{l} V R P^{D Y}$ & $\overline{I I L L I Q}^{N Y S E}$ & "ILLIQ $Q^{S P 500}$ & $\begin{array}{l}P D \\
\end{array}$ & $P$ PE & 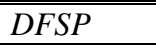 & $\overline{~ T M S P}$ & RREL & CAAY \\
\hline$V W$ & 1.000 & & & & & & & & & & & & \\
\hline INDEX & $0.983 * * *$ & 1.000 & & & & & & & & & & & \\
\hline$V R P^{B T Z}$ & 0.017 & -0.002 & 1.000 & & & & & & & & & & \\
\hline$V R P^{C W}$ & -0.024 & -0.030 & $0.306 * * *$ & 1.000 & & & & & & & & & \\
\hline$V R P^{D Y}$ & $-0.578 * * *$ & $-0.567 * * *$ & $0.108 * *$ & $0.122 * *$ & 1.000 & & & & & & & & \\
\hline$I L L I Q^{N Y S E}$ & -0.027 & -0.028 & $0.219 * * *$ & $0.205^{* * *}$ & $0.129 * *$ & 1.000 & & & & & & & \\
\hline ILLIQ $Q^{\text {SP500 }}$ & -0.013 & -0.013 & $0.216^{* * *}$ & $0.193 * * *$ & $0.128 * *$ & $0.973 * * *$ & 1.000 & & & & & & \\
\hline$P D$ & 0.003 & -0.019 & $0.207 * * *$ & $0.172 * * *$ & $0.189 * * *$ & $0.088^{*}$ & 0.015 & 1.000 & & & & & \\
\hline$P E$ & 0.012 & 0.008 & 0.076 & -0.028 & 0.044 & $-0.399 * * *$ & $-0.421 * * *$ & $0.177 * * *$ & 1.000 & & & & \\
\hline$D F S P$ & $-0.104 *$ & $-0.119 * *$ & -0.032 & $0.149 * * *$ & $0.181 * * *$ & -0.061 & $-0.123 * *$ & $0.490 * * *$ & $-0.279 * * *$ & 1.000 & & & \\
\hline TMSP & 0.000 & -0.014 & -0.036 & -0.003 & 0.003 & $0.128 * *$ & 0.084 & $0.187 * * *$ & $-0.370 * * *$ & $0.244 * * *$ & 1.000 & & \\
\hline$R R E L$ & 0.046 & 0.064 & $-0.242 * * *$ & $-0.179 * * *$ & $-0.121 * *$ & $-0.329 * * *$ & $-0.248 * * *$ & $-0.492 * * *$ & $0.206^{* * *}$ & $-0.446 * * *$ & $-0.365 * * *$ & 1.000 & \\
\hline$C A Y$ & -0.069 & -0.065 & $0.235 * * *$ & $0.153 * * *$ & $0.234 * * *$ & $0.731 * * *$ & $0.771^{* * *}$ & 0.015 & $-0.247 * * *$ & -0.043 & $0.112 * *$ & $-0.195 * * *$ & 1.000 \\
\hline
\end{tabular}

This table shows the correlations between variables used in this study. The variables are liquidity measures (ILLIQ $Q^{N Y S E}$ and $\left.I L L I Q^{S P 500}\right)$, the variance risk premium $\left(V R P^{B T Z}\right.$, $V R P^{C W}$ and $\left.V R P^{D Y}\right)$, return proxies ( $V W$ and INDEX) and control variables (PD, PE, DFSP, TMSP, RREL and CAY). The analysis uses monthly data from January 1990 to

December 2018. And *,**, and *** indicate statistical significance at the $10 \%, 5 \%$, and $1 \%$ level, respectively. 
Table 3. The tri-variate Toda-Yamamoto Granger non-causality test results

\begin{tabular}{|c|c|c|c|c|c|c|}
\hline & \multicolumn{6}{|c|}{$\mathrm{X} 1: V W$} \\
\hline & $\mathrm{X} 1->\mathrm{X} 2$ & $\mathrm{X} 2->\mathrm{X} 1$ & $\mathrm{X} 1->\mathrm{X} 3$ & X3->X1 & $\mathrm{X} 2->\mathrm{X} 3$ & $\mathrm{X} 3->\mathrm{X} 2$ \\
\hline $\mathrm{X} 2: V R P^{B T Z} ; \mathrm{X} 3: I L L I Q^{N Y S E}$ & 0.8719 & 0.0001 & 0.0000 & 0.7808 & 0.3821 & 0.7458 \\
\hline $\mathrm{X} 2: V R P^{B T Z} ; \mathrm{X} 3: I L L I Q^{S P 500}$ & 0.8726 & 0.0001 & 0.0000 & 0.7236 & 0.1066 & 0.8180 \\
\hline $\mathrm{X} 2: V R P^{C W} ; \mathrm{X} 3: I L L I Q^{N Y S E}$ & 0.3482 & 0.0000 & 0.0000 & 0.8935 & 0.0000 & 0.3429 \\
\hline $\mathrm{X} 2: V R P^{C W} ; \mathrm{X} 3: I L L I Q^{S P 500}$ & 0.2592 & 0.0000 & 0.0000 & 0.8592 & 0.0000 & 0.6330 \\
\hline $\mathrm{X} 2: V R P^{D Y} ; \mathrm{X} 3: I L L I Q^{N Y S E}$ & 0.1372 & 0.0003 & 0.0000 & 0.3761 & 0.0037 & 0.8248 \\
\hline \multirow[t]{3}{*}{$\mathrm{X} 2: V R P^{D Y} ; \mathrm{X} 3: I L L I Q^{S P 500}$} & 0.1595 & 0.0003 & 0.0000 & 0.2447 & 0.0000 & 0.9998 \\
\hline & \multicolumn{6}{|c|}{$\mathrm{X} 1: I N D E X$} \\
\hline & $\mathrm{X} 1->\mathrm{X} 2$ & $\mathrm{X} 2->\mathrm{X} 1$ & $\mathrm{X} 1->\mathrm{X} 3$ & $\mathrm{X} 3->\mathrm{X} 1$ & $\mathrm{X} 2->\mathrm{X} 3$ & $\mathrm{X} 3->\mathrm{X} 2$ \\
\hline $\mathrm{X} 2: V R P^{B T Z} ; \mathrm{X} 3: I L L I Q^{N Y S E}$ & 0.9159 & 0.0002 & 0.0000 & 0.8083 & 0.7285 & 0.6834 \\
\hline $\mathrm{X} 2: V R P^{B T Z} ; \mathrm{X} 3: I_{L L I} Q^{S P 500}$ & 0.9292 & 0.0003 & 0.0000 & 0.7938 & 0.1858 & 0.7895 \\
\hline $\mathrm{X} 2: V R P^{C W} ; \mathrm{X} 3: I L L I Q^{N Y S E}$ & 0.3669 & 0.0000 & 0.0000 & 0.9954 & 0.0000 & 0.2999 \\
\hline $\mathrm{X} 2: V R P^{C W} ; \mathrm{X} 3: I L L I Q^{S P 500}$ & 0.2779 & 0.0000 & 0.0000 & 0.9711 & 0.0000 & 0.5768 \\
\hline $\mathrm{X} 2: V R P^{D Y} ; \mathrm{X} 3: I L L I Q^{N Y S E}$ & 0.1115 & 0.0004 & 0.0000 & 0.4605 & 0.0012 & 0.8218 \\
\hline $\mathrm{X} 2: V R P^{D Y} ; \mathrm{X} 3: I L L I Q^{S P 500}$ & 0.1475 & 0.0001 & 0.0002 & 0.1999 & 0.0000 & 0.9988 \\
\hline
\end{tabular}

This table summarizes the $p$-value of the chi-square statistics for the Toda-Yamamoto Granger non-causality tests based on tri-variate VAR models. It tests the relation between the VRP, stock returns and illiquidity. The analysis uses monthly data from full sample period January 1990 to December 2018. 
Table 4. The tri-variate Toda-Yamamoto Granger non-causality test results with control variables

\begin{tabular}{|c|c|c|c|c|c|c|}
\hline & \multicolumn{6}{|c|}{$\mathrm{X} 1: V W$} \\
\hline & $X 1->X 2$ & $\mathrm{X} 2->\mathrm{X} 1$ & $X 1->X 3$ & $\mathrm{X} 3->\mathrm{X} 1$ & $\mathrm{X} 2->\mathrm{X} 3$ & $\mathrm{X} 3->\mathrm{X} 2$ \\
\hline $\mathrm{X} 2: V R P^{B T Z} ; \mathrm{X} 3: I L L I Q^{N Y S E}$ & 0.3855 & 0.0000 & 0.0000 & 0.7565 & 0.3215 & 0.4706 \\
\hline $\mathrm{X} 2: V R P^{B T Z} ; \mathrm{X} 3: I L L I Q^{S P 500}$ & 0.3646 & 0.0000 & 0.0000 & 0.2413 & 0.1142 & 0.4146 \\
\hline $\mathrm{X} 2: V R P^{C W} ; \mathrm{X} 3: I L L I Q^{N Y S E}$ & 0.7397 & 0.0000 & 0.0000 & 0.6769 & 0.0000 & 0.2527 \\
\hline $\mathrm{X} 2: V R P^{C W} ; \mathrm{X} 3: I L L I Q^{S P 500}$ & 0.6265 & 0.0000 & 0.0000 & 0.3958 & 0.0000 & 0.4125 \\
\hline $\mathrm{X} 2: V R P^{D Y} ; \mathrm{X} 3: I L L I Q^{N Y S E}$ & 0.1319 & 0.0000 & 0.0000 & 0.6803 & 0.0036 & 0.1814 \\
\hline \multirow[t]{3}{*}{$\mathrm{X} 2: V R P^{D Y} ; \mathrm{X} 3: I L L I Q^{S P 500}$} & 0.1038 & 0.0000 & 0.0001 & 0.1203 & 0.0001 & 0.3950 \\
\hline & \multicolumn{6}{|c|}{$\mathrm{X} 1: I N D E X$} \\
\hline & $\mathrm{X} 1->\mathrm{X} 2$ & $\mathrm{X} 2->\mathrm{X} 1$ & $\mathrm{X} 1->\mathrm{X} 3$ & $\mathrm{X} 3->\mathrm{X} 1$ & $\mathrm{X} 2->\mathrm{X} 3$ & $\mathrm{X} 3->\mathrm{X} 2$ \\
\hline $\mathrm{X} 2: V R P^{B T Z} ; \mathrm{X} 3: I L L I Q^{N Y S E}$ & 0.4161 & 0.0000 & 0.0000 & 0.6286 & 0.4863 & 0.4656 \\
\hline $\mathrm{X} 2: V R P^{B T Z} ; \mathrm{X} 3: I L L I Q^{S P 500}$ & 0.3945 & 0.0000 & 0.0000 & 0.2937 & 0.1673 & 0.4129 \\
\hline $\mathrm{X} 2: V R P^{C W} ; \mathrm{X} 3: I L L I Q^{N Y S E}$ & 0.7992 & 0.0000 & 0.0000 & 0.6862 & 0.0000 & 0.2229 \\
\hline $\mathrm{X} 2: V R P^{C W} ; \mathrm{X} 3: I L L I Q^{S P 500}$ & 0.6975 & 0.0000 & 0.0000 & 0.3688 & 0.0000 & 0.3655 \\
\hline $\mathrm{X} 2: V R P^{D Y} ; \mathrm{X} 3: I L L I Q^{N Y S E}$ & 0.1335 & 0.0000 & 0.0000 & 0.2085 & 0.0023 & 0.7006 \\
\hline $\mathrm{X} 2: V R P^{D Y} ; \mathrm{X} 3: I L L I Q^{S P 500}$ & 0.1047 & 0.0000 & 0.0004 & 0.1802 & 0.0001 & 0.3841 \\
\hline
\end{tabular}

This table summarizes the $p$-value of the chi-square statistics for the Toda-Yamamoto Granger non-causality tests based on tri-variate VAR models with control variables (PD, PE, DFSP, TMSP, RREL and CAY). It tests the relation between the VRP, stock returns and illiquidity. The analysis uses monthly data from full sample period January 1990 to December 2018. 
Table 5. The Toda-Yamamoto Granger non-causality test results

Panel A. VRP \& Stock Returns, ILLIQ \& Stock Returns

\begin{tabular}{|c|c|c|c|c|c|}
\hline & $\mathrm{X} 1$ & \multicolumn{2}{|c|}{$V W$} & \multicolumn{2}{|c|}{$I N D E X$} \\
\hline $\mathrm{X} 2$ & Sample period & $\mathrm{X} 1->\mathrm{X} 2$ & $\mathrm{X} 2->\mathrm{X} 1$ & $\mathrm{X} 1->\mathrm{X} 2$ & $\mathrm{X} 2->\mathrm{X} 1$ \\
\hline \multirow{5}{*}{$V R P^{B T Z}$} & $1990-2018$ & 0.8191 & 0.0000 & 0.8907 & 0.0000 \\
\hline & 1990-2012 & 0.9270 & 0.0000 & 0.8227 & 0.0000 \\
\hline & $1992-2014$ & 0.8939 & 0.0000 & 0.7530 & 0.0000 \\
\hline & 1994-2016 & 0.6635 & 0.0000 & 0.6370 & 0.0000 \\
\hline & 1996-2018 & 0.7318 & 0.0000 & 0.7993 & 0.0000 \\
\hline \multirow{5}{*}{$V R P^{C W}$} & $1990-2018$ & 0.1960 & 0.0000 & 0.2216 & 0.0000 \\
\hline & $1990-2012$ & 0.2890 & 0.0000 & 0.5339 & 0.0000 \\
\hline & $1992-2014$ & 0.1895 & 0.0000 & 0.4700 & 0.0000 \\
\hline & 1994-2016 & 0.1789 & 0.0000 & 0.4669 & 0.0000 \\
\hline & 1996-2018 & 0.1244 & 0.0000 & 0.1588 & 0.0000 \\
\hline \multirow{5}{*}{$V R P^{D Y}$} & $1990-2018$ & 0.2341 & 0.0003 & 0.2217 & 0.0006 \\
\hline & 1990-2012 & 0.2820 & 0.0003 & 0.3415 & 0.0017 \\
\hline & $1992-2014$ & 0.1711 & 0.0005 & 0.2857 & 0.0043 \\
\hline & 1994-2016 & 0.2060 & 0.0003 & 0.1800 & 0.0021 \\
\hline & 1996-2018 & 0.2109 & 0.0017 & 0.1809 & 0.0032 \\
\hline \multirow{5}{*}{$I L L I Q^{N Y S E}$} & $1990-2018$ & 0.0000 & 0.4202 & 0.0000 & 0.4901 \\
\hline & $1990-2012$ & 0.0000 & 0.8875 & 0.0000 & 0.9109 \\
\hline & $1992-2014$ & 0.0000 & 0.5548 & 0.0000 & 0.3135 \\
\hline & 1994-2016 & 0.0000 & 0.5679 & 0.0000 & 0.2129 \\
\hline & 1996-2018 & 0.0000 & 0.3667 & 0.0000 & 0.1900 \\
\hline \multirow{5}{*}{$I L L I Q^{S P 500}$} & $1990-2018$ & 0.0000 & 0.2658 & 0.0000 & 0.3422 \\
\hline & $1990-2012$ & 0.0000 & 0.2063 & 0.0000 & 0.3203 \\
\hline & $1992-2014$ & 0.0000 & 0.7191 & 0.0000 & 0.9070 \\
\hline & 1994-2016 & 0.0000 & 0.5546 & 0.0000 & 0.9131 \\
\hline & 1996-2018 & 0.0000 & 0.5375 & 0.0000 & 0.6293 \\
\hline
\end{tabular}

Panel B. VRP \& ILLIQ

\begin{tabular}{c|c|cc|cc|cc}
\hline \hline & $\mathrm{X} 1$ & \multicolumn{2}{|c|}{$V R P^{B T Z}$} & \multicolumn{2}{c|}{$V R P^{C W}$} & \multicolumn{2}{c}{$V R P^{D Y}$} \\
\hline $\mathrm{X} 2$ & Sample period & $\mathrm{X} 1->\mathrm{X} 2$ & $\mathrm{X} 2->\mathrm{X} 1$ & $\mathrm{X} 1->\mathrm{X} 2$ & $\mathrm{X} 2->\mathrm{X} 1$ & $\mathrm{X} 1->\mathrm{X} 2$ & $\mathrm{X} 2->\mathrm{X} 1$ \\
\hline \multirow{5}{*}{ ILLIQ $^{\text {NYSE }}$} & $1990-2018$ & 0.0523 & 0.4152 & 0.0000 & 0.1506 & 0.0000 & 0.6424 \\
& $1990-2012$ & 0.0773 & 0.4937 & 0.0000 & 0.1975 & 0.0000 & 0.7214 \\
& $1992-2014$ & 0.0756 & 0.4784 & 0.0000 & 0.3404 & 0.0000 & 0.7859 \\
& $1994-2016$ & 0.0721 & 0.6726 & 0.0000 & 0.2507 & 0.0000 & 0.6875 \\
& $1996-2018$ & 0.0754 & 0.5022 & 0.0000 & 0.2945 & 0.0000 & 0.5893 \\
\hline \multirow{5}{*}{ ILLIQ } & $1990-2018$ & 0.0847 & 0.5096 & 0.0000 & 0.1727 & 0.0000 & 0.2958 \\
& $1990-2012$ & 0.0700 & 0.4817 & 0.0000 & 0.1694 & 0.0000 & 0.5266 \\
& $1992-2014$ & 0.1249 & 0.6360 & 0.0000 & 0.3618 & 0.0000 & 0.3581 \\
& $1994-2016$ & 0.2057 & 0.6987 & 0.0000 & 0.3670 & 0.0000 & 0.3564 \\
& $1996-2018$ & 0.2271 & 0.6518 & 0.0000 & 0.4963 & 0.0000 & 0.3910 \\
\hline \hline
\end{tabular}

This table summarizes the $p$-value of the chi-square statistics for the Toda-Yamamoto Granger non-causality test between the VRP and stock returns (Panel A), between illiquidity and stock returns (Panel A), and between the VRP and illiquidity (Panel B). The analysis uses monthly data for the full sample period from January 1990 to December 2018, and four sub-samples from January 1990 to December 2012, January 1992 to December 2014, January 1994 to December 2016, and January 1996 to December 2018. 
Table 6. The Toda-Yamamoto Granger non-causality test results with control variables

Panel A. VRP \& Stock Returns, ILLIQ \& Stock Returns

\begin{tabular}{|c|c|c|c|c|c|}
\hline \multirow[b]{2}{*}{$\mathrm{X} 2$} & \multirow{2}{*}{$\frac{\mathrm{X} 1}{\text { Sample period }}$} & \multicolumn{2}{|c|}{$V W$} & \multicolumn{2}{|c|}{ INDEX } \\
\hline & & $\mathrm{X} 1->\mathrm{X} 2$ & $\mathrm{X} 2->\mathrm{X} 1$ & $X 1->X 2$ & $\mathrm{X} 2->\mathrm{X} 1$ \\
\hline \multirow{5}{*}{$V R P^{B T Z}$} & 1990-2018 & 0.8096 & 0.0000 & 0.8565 & 0.0000 \\
\hline & $1990-2012$ & 0.9511 & 0.0000 & 0.8317 & 0.0000 \\
\hline & $1992-2014$ & 0.2482 & 0.0000 & 0.1402 & 0.0000 \\
\hline & 1994-2016 & 0.2574 & 0.0000 & 0.1547 & 0.0000 \\
\hline & 1996-2018 & 0.1659 & 0.0000 & 0.1856 & 0.0000 \\
\hline \multirow{5}{*}{$V R P^{C W}$} & $1990-2018$ & 0.2411 & 0.0000 & 0.2292 & 0.0000 \\
\hline & $1990-2012$ & 0.3862 & 0.0000 & 0.5437 & 0.0000 \\
\hline & $1992-2014$ & 0.3141 & 0.0000 & 0.4662 & 0.0000 \\
\hline & 1994-2016 & 0.3062 & 0.0000 & 0.4848 & 0.0000 \\
\hline & 1996-2018 & 0.5116 & 0.0000 & 0.4789 & 0.0000 \\
\hline \multirow{5}{*}{$V R P^{D Y}$} & $1990-2018$ & 0.1200 & 0.0000 & 0.1174 & 0.0000 \\
\hline & $1990-2012$ & 0.1814 & 0.0000 & 0.1847 & 0.0000 \\
\hline & $1992-2014$ & 0.2122 & 0.0000 & 0.2162 & 0.0001 \\
\hline & 1994-2016 & 0.1038 & 0.0000 & 0.1911 & 0.0002 \\
\hline & 1996-2018 & 0.1055 & 0.0000 & 0.1027 & 0.0000 \\
\hline \multirow{5}{*}{$I L L I Q^{N Y S E}$} & $1990-2018$ & 0.0000 & 0.8620 & 0.0000 & 0.8800 \\
\hline & $1990-2012$ & 0.0000 & 0.7159 & 0.0000 & 0.7729 \\
\hline & $1992-2014$ & 0.0000 & 0.2280 & 0.0000 & 0.2983 \\
\hline & 1994-2016 & 0.0000 & 0.2395 & 0.0000 & 0.2483 \\
\hline & 1996-2018 & 0.0000 & 0.7489 & 0.0000 & 0.3281 \\
\hline \multirow{5}{*}{$I L L I Q^{S P 500}$} & $1990-2018$ & 0.0000 & 0.3150 & 0.0000 & 0.2757 \\
\hline & $1990-2012$ & 0.0000 & 0.2386 & 0.0000 & 0.2939 \\
\hline & $1992-2014$ & 0.0000 & 0.6036 & 0.0000 & 0.8403 \\
\hline & 1994-2016 & 0.0000 & 0.6241 & 0.0000 & 0.8960 \\
\hline & $1996-2018$ & 0.0000 & 0.6138 & 0.0000 & 0.6940 \\
\hline
\end{tabular}

Panel B. VRP \& ILLIQ

\begin{tabular}{|c|c|c|c|c|c|c|c|}
\hline & $\mathrm{X} 1$ & \multicolumn{2}{|c|}{$V R P^{B T Z}$} & \multicolumn{2}{|c|}{$V R P^{C W}$} & \multicolumn{2}{|c|}{$V R P^{D Y}$} \\
\hline $\mathrm{X} 2$ & Sample period & $\mathrm{X} 1->\mathrm{X} 2$ & $\mathrm{X} 2->\mathrm{X} 1$ & $\mathrm{X} 1->\mathrm{X} 2$ & $\mathrm{X} 2->\mathrm{X} 1$ & $\mathrm{X} 1->\mathrm{X} 2$ & $\mathrm{X} 2->\mathrm{X} 1$ \\
\hline \multirow{5}{*}{$I L L I Q^{N Y S E}$} & $1990-2018$ & 0.0563 & 0.4896 & 0.0000 & 0.2895 & 0.0000 & 0.759 \\
\hline & $1990-2012$ & 0.0612 & 0.8494 & 0.0000 & 0.2970 & 0.0000 & 0.8581 \\
\hline & $1992-2014$ & 0.0648 & 0.6193 & 0.0000 & 0.4582 & 0.0000 & 0.9026 \\
\hline & 1994-2016 & 0.0696 & 0.5891 & 0.0000 & 0.3503 & 0.0000 & 0.7789 \\
\hline & 1996-2018 & 0.0966 & 0.8408 & 0.0000 & 0.2583 & 0.0000 & 0.8247 \\
\hline \multirow{5}{*}{$I L L I Q^{S P 500}$} & $1990-2018$ & 0.1353 & 0.4500 & 0.0000 & 0.2899 & 0.0000 & 0.7017 \\
\hline & $1990-2012$ & 0.0901 & 0.6555 & 0.0000 & 0.2441 & 0.0000 & 0.8433 \\
\hline & $1992-2014$ & 0.0830 & 0.6889 & 0.0000 & 0.6371 & 0.0000 & 0.6114 \\
\hline & 1994-2016 & 0.0660 & 0.7745 & 0.0000 & 0.4843 & 0.0000 & 0.7843 \\
\hline & 1996-2018 & 0.2536 & 0.9340 & 0.0000 & 0.3756 & 0.0000 & 0.5459 \\
\hline
\end{tabular}

This table summarizes the $p$-value of the chi-square statistics for the Toda-Yamamoto Granger non-causality test with control variables (PD, PE, DFSP, TMSP, RREL and CAY) between the VRP and stock returns (Panel A), between illiquidity and stock returns (Panel A), and between the VRP and illiquidity (Panel B). The analysis uses monthly data for the full sample from January 1990 to December 2018, and four sub-samples from January 1990 to December 2012, January 1992 to December 2014, January 1994 to December 2016, and January 1996 to December 2018. 
Figure 1. Generalized impulse response functions for sock returns, illiquidity and the VRP with control variables

Panel A. The response of $V W$

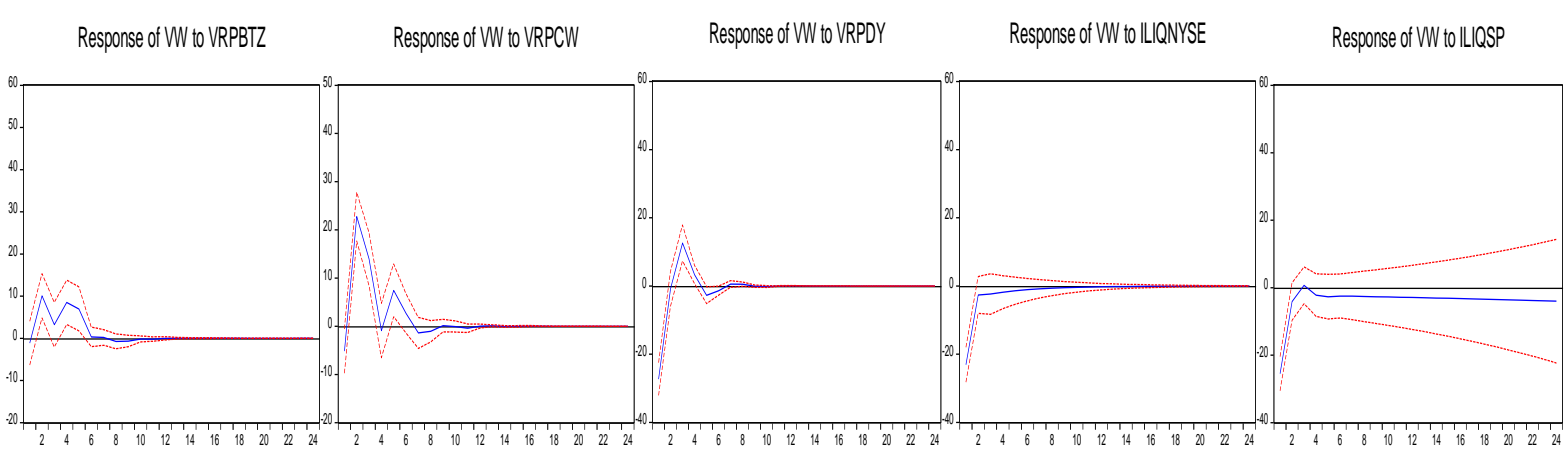

Panel B. The response of INDEX

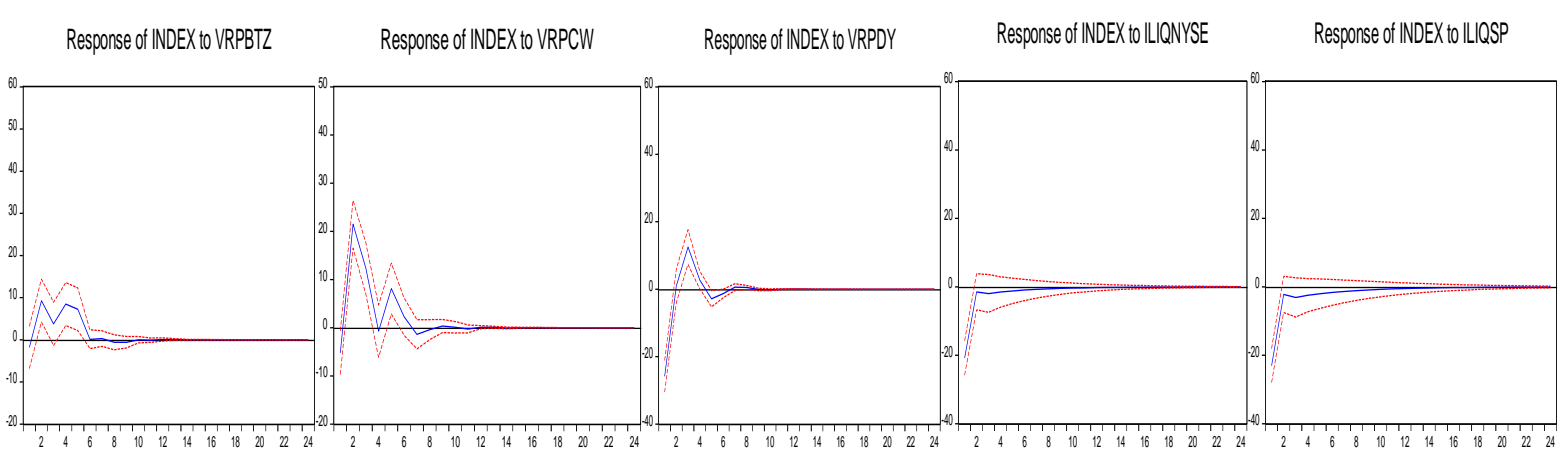

Panel C. The response of ILLIQ $Q^{N Y S E}$

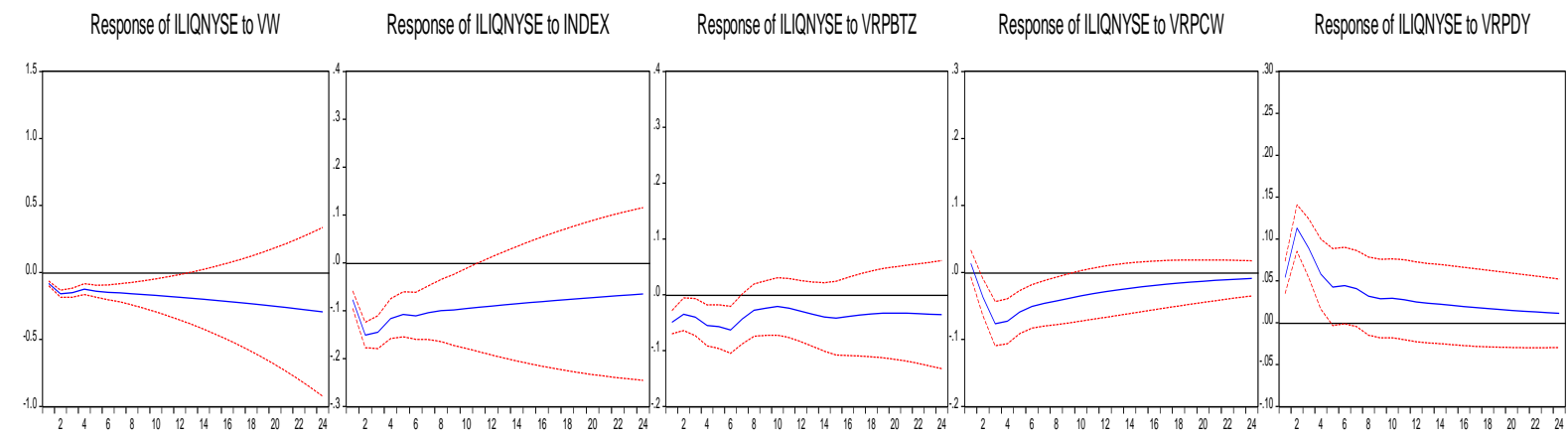

Panel D. The response of ILLIQ $Q^{S P 500}$

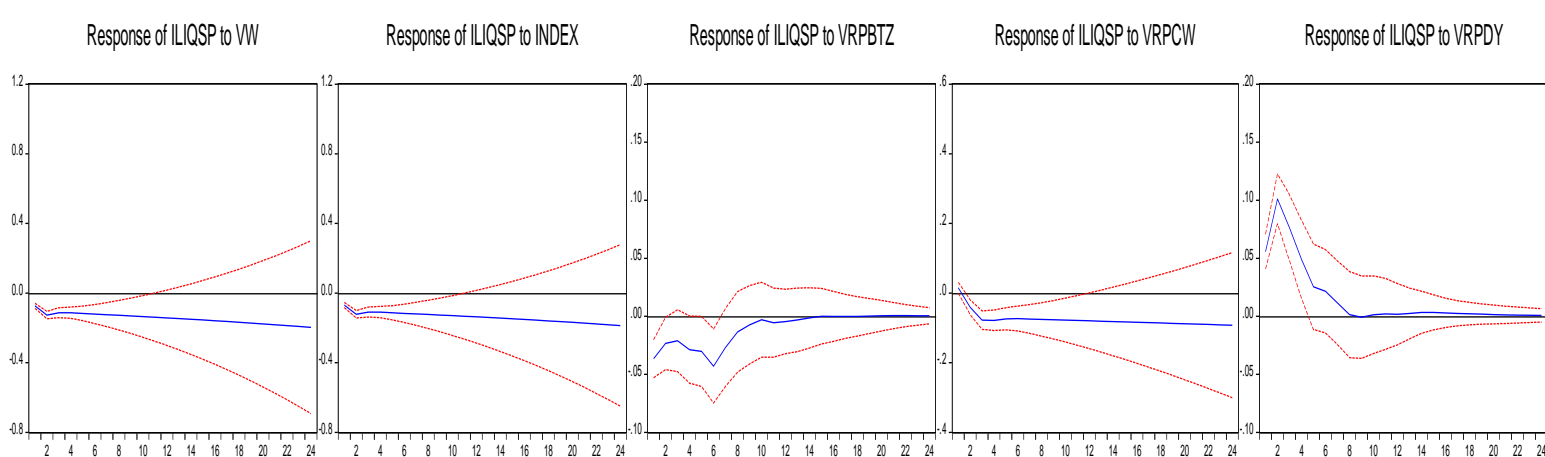


Panel E. The response of $V R P^{B T Z}$

Response of VRPBTZ to VW

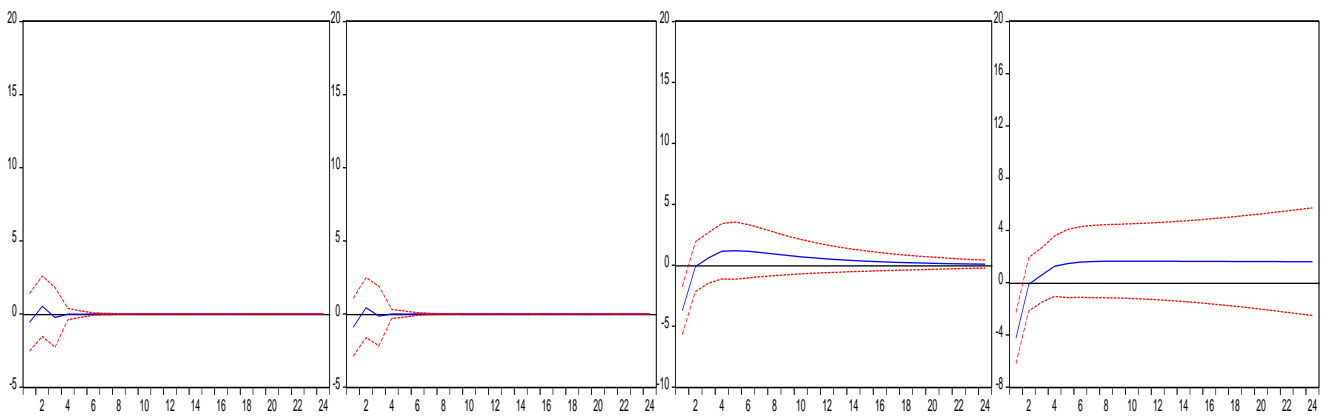

Panel F. The response of $V R P^{C W}$

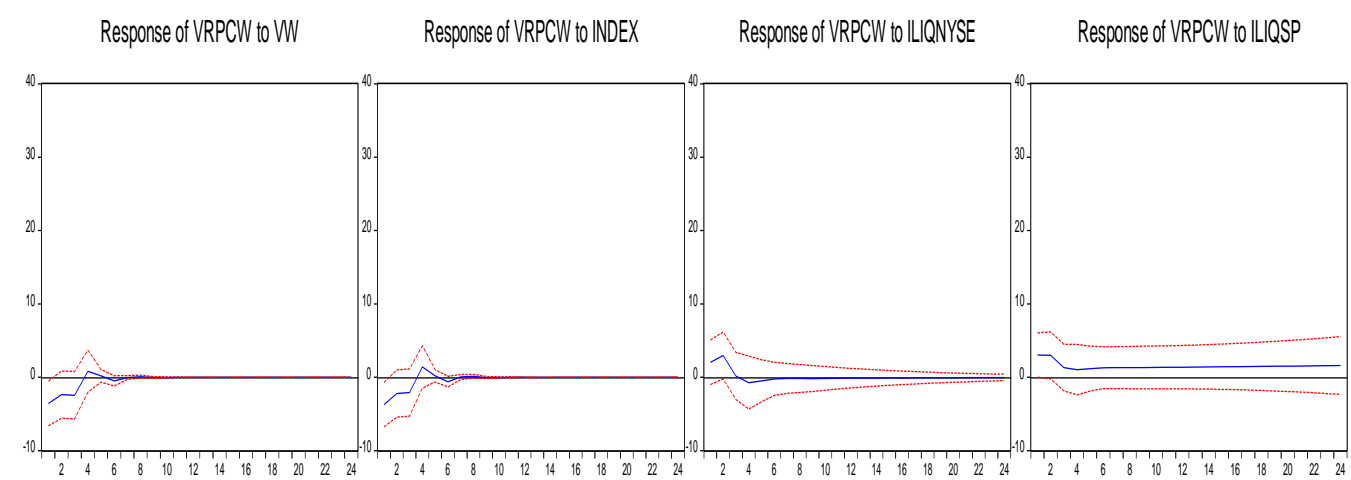

Panel G. The Response of $V R P^{D Y}$

Response of VRPDY to WW

Response of VRPDY to INDEX

Response of VRPDY to LLLNYSE

Response of VRPDY to LLQSP

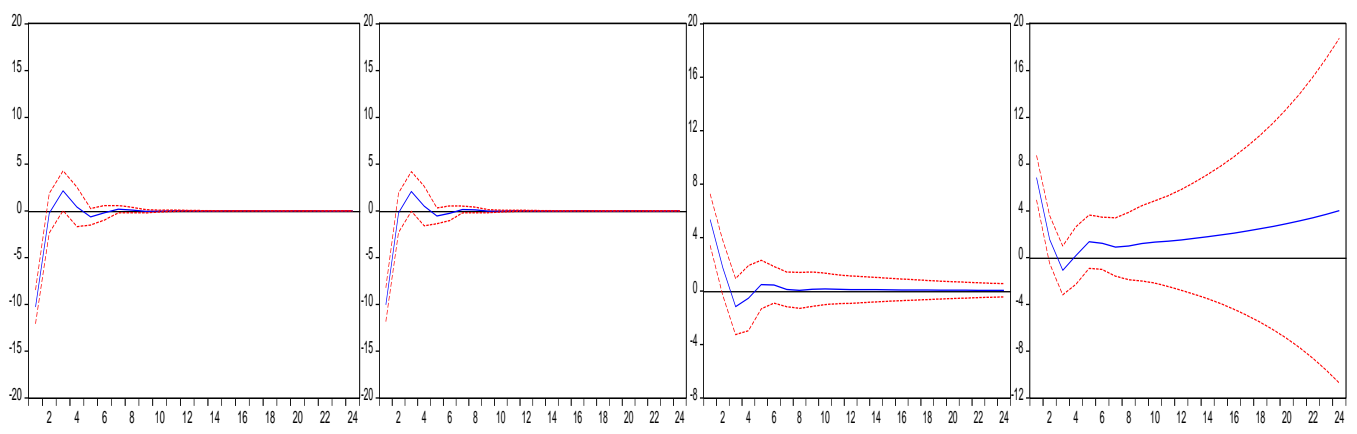

This figure plots the estimated generalized impulse response functions for illiquidity, stock returns and the VRP with control variables (PD, PE, DFSP, TMSP, RREL and CAY) for 24 months. These figures are based on the VAR model for the full sample period from January 1990 to December 2018. Panel A presents generalized the impulse response function for $V W$ following a one-standard-deviation innovation in illiquidity and the VRP. Panel B presents the generalized impulse response function for INDEX to illiquidity and the VRP. Panel C illustrates the response of illiquidity of NYSE to one unit change in index returns and the VRP. Panel D reports the response for illiquidity for S\&P500 index to the change in stock returns and the VRP. The generalized impulse response functions for the VRP to the illiquidity and stock returns are reported in Panel E, Panel F and Panel G, respectively. The solid lines are the response of each variable in the month (the horizontal axis of each figure) following one-standard-deviation shock in another variable. The magnitude of the response, measured as percentage change, is reported on the vertical axis. The dashed lines are the confidence intervals with two standard errors. 
Table 7. Return predictability of the VRP and illiquidity

Panel A. Predictive regression

\begin{tabular}{|c|c|c|c|c|c|c|c|}
\hline & \multicolumn{7}{|c|}{ Dependent Variable: $V W$} \\
\hline & \multicolumn{3}{|c|}{ In Sample } & \multicolumn{2}{|c|}{$\begin{array}{c}\text { Out-of-sample } \\
\text { After } 2000\end{array}$} & \multicolumn{2}{|c|}{$\begin{array}{c}\text { Out-of-sample } \\
\text { After } 2005\end{array}$} \\
\hline & (1) & (2) & (3) & (4) & (5) & (6) & (7) \\
\hline & Beta & $t$-stat & $R^{2}(\%)$ & $R^{2}$ OS $(\%)$ & MSFE-adjusted & $R^{2} \mathrm{OS}(\%)$ & MSFE-adjusted \\
\hline$V R P^{B T Z}$ & $0.600 * * *$ & 4.311 & 5.747 & 6.307 & $2.199 * *$ & 9.268 & $2.079 * *$ \\
\hline$V R P^{C W}$ & $0.792 * * *$ & 5.999 & 22.277 & 21.269 & $2.060 * *$ & 23.736 & $1.759 * *$ \\
\hline$V R P^{D Y}$ & -0.316 & -0.636 & 0.103 & -2.891 & -1.037 & -4.224 & -1.075 \\
\hline ILLIQ $Q^{N Y S E}$ & 1.365 & 0.835 & 0.158 & -0.510 & -0.378 & -0.481 & -0.116 \\
\hline \multirow[t]{5}{*}{ ILLIQ $Q^{S P 500}$} & 1.466 & 0.961 & 0.458 & -0.863 & -0.116 & -0.864 & -0.084 \\
\hline & \multicolumn{7}{|c|}{ Dependent Variable: Index } \\
\hline & \multicolumn{3}{|c|}{ In-sample } & \multicolumn{2}{|c|}{$\begin{array}{c}\text { Out-of-sample } \\
\text { After } 2000 \\
\end{array}$} & \multicolumn{2}{|c|}{$\begin{array}{l}\text { Out-of-sample } \\
\text { After } 2005\end{array}$} \\
\hline & (1) & (2) & (3) & (4) & $(5)$ & (6) & (7) \\
\hline & Beta & $t$-stat & $R^{2}(\%)$ & $R^{2}$ OS $(\%)$ & MSFE-adjusted & $R^{2}$ OS $(\%)$ & MSFE-adjusted \\
\hline$V R P^{B T Z}$ & $0.567 * * *$ & 3.981 & 5.449 & 5.546 & $2.145^{* *}$ & 8.318 & $2.056^{* *}$ \\
\hline$V R P^{C W}$ & $0.733 * * *$ & 5.760 & 20.238 & 18.104 & $2.037 * *$ & 21.050 & $0.039 * *$ \\
\hline$V R P^{D Y}$ & -0.013 & -0.054 & 0.003 & -3.410 & -1.073 & -5.173 & -1.210 \\
\hline$I L L I Q^{N Y S E}$ & 1.092 & 0.675 & 0.108 & -0.710 & -0.592 & -0.511 & -0.107 \\
\hline$I L L I Q^{S P 500}$ & 1.281 & 0.847 & 0.161 & -1.120 & -0.160 & -1.033 & -0.015 \\
\hline
\end{tabular}

Panel B. Predictive regression with control variables

\begin{tabular}{|c|c|c|c|c|c|c|}
\hline & \multicolumn{3}{|c|}{ Dependent Variable: $V W$} & \multicolumn{3}{|c|}{ Dependent Variable: Index } \\
\hline & (1) & $(2)$ & (3) & (4) & (5) & (6) \\
\hline & Beta & $t$-stat & $R^{2}(\%)$ & Beta & $t$-stat & $R^{2}(\%)$ \\
\hline Macro & & & 1.050 & & & 1.331 \\
\hline Macro $+V R P^{B T Z}$ & $0.648 * * *$ & 4.303 & 7.141 & $0.615^{* * *}$ & 3.822 & 7.149 \\
\hline$M a c r o+V R P^{C W}$ & $0.850 * * *$ & 5.153 & 25.130 & $0.794 * * *$ & 4.893 & 23.631 \\
\hline$M a c r o+V R P^{D Y}$ & -0.050 & -0.199 & 1.086 & 0.029 & 0.121 & 1.335 \\
\hline Macro $+I L L I Q^{N Y S E}$ & -1.518 & -0.379 & 1.110 & -2.044 & -0.541 & 1.435 \\
\hline Macro+ILLIQ $Q^{S P 500}$ & -2.346 & -0.491 & 1.158 & -2.883 & -0.661 & 1.497 \\
\hline
\end{tabular}

Panel A reports the in-sample and out-of-sample predictive regression results. For the in-sample test, we present the estimated coefficients, the heteroscedasticity-robust $t$-statistics, and the $R^{2}$ statistics. For the out-of-sample test, we report the out-of-sample $R^{2}\left(R^{2}\right.$ OS) of Campbell and Thompson (2008), and the MSFE-adjusted statistic of Clark and West (2007). Column (4) - (5) contain the results when we use 1990:01 - 1999:12 as the initial estimation period and 2000:01 - 2018:12 as the forecast evaluation period. Column (6) - (7) contain the results when we use 1990:01 - 2004:12 as the initial estimation period and 2005:01 - 2018:12 as the forecast evaluation period. Panel B reports the forecasting results controlling for the principle component factor of 14 US macroeconomic variables in Welch and Goyal (2008), namely, log dividend-price ratio, log dividend yield, log earnings-price ratio, log dividend-payout ratio, equity risk premium volatility, book-to-market ratio, net equity expansion, Treasury bill rate, long-term bond yield, long-term bond return, term spread, default yield spread, default return spread, inflation rate. And *,**, and *** indicate statistical significance at the $10 \%, 5 \%$, and $1 \%$ level, respectively. 
Table 8. The tri-variate Toda-Yamamoto Granger non-causality test with alternative liquidity measure

\begin{tabular}{l|cccccc}
\hline \hline & \multicolumn{7}{|c}{$\mathrm{X} 1: V W$} \\
\cline { 2 - 7 } & $\mathrm{X} 1->\mathrm{X} 2$ & $\mathrm{X} 2->\mathrm{X} 1$ & $\mathrm{X} 1->\mathrm{X} 3$ & $\mathrm{X} 3->\mathrm{X} 1$ & $\mathrm{X} 2->\mathrm{X} 3$ & $\mathrm{X} 3->\mathrm{X} 2$ \\
\hline $\mathrm{X} 2: V R P^{B T Z} ; \mathrm{X} 3: L M^{N Y S E}$ & 0.8427 & 0.0000 & 0.0007 & 0.4493 & 0.1124 & 0.1836 \\
$\mathrm{X} 2: V R P^{B T Z} ; \mathrm{X} 3: L M^{S P 500}$ & 0.8191 & 0.0000 & 0.0220 & 0.5165 & 0.4939 & 0.6293 \\
$\mathrm{X} 2: V R P^{C W} ; \mathrm{X} 3: L M^{N Y S E}$ & 0.5404 & 0.0000 & 0.0011 & 0.1167 & 0.0785 & 0.6938 \\
$\mathrm{X} 2: V R P^{C W} ; \mathrm{X} 3: L M^{S P 500}$ & 0.4484 & 0.0000 & 0.0162 & 0.2919 & 0.0026 & 0.8538 \\
$\mathrm{X} 2: V R P^{D Y} ; \mathrm{X} 3: L M^{N Y S E}$ & 0.1668 & 0.0000 & 0.0028 & 0.5300 & 0.0552 & 0.5766 \\
$\mathrm{X} 2: V R P^{D Y} ; \mathrm{X} 3: L M^{S P 500}$ & 0.1143 & 0.0000 & 0.0354 & 0.2171 & 0.0332 & 0.4906 \\
\hline
\end{tabular}

\begin{tabular}{l|cccccc}
\hline & \multicolumn{7}{|c}{$\mathrm{X} 1: I N D E X$} \\
\cline { 2 - 7 } & $\mathrm{X} 1->\mathrm{X} 2$ & $\mathrm{X} 2->\mathrm{X} 1$ & $\mathrm{X} 1->\mathrm{X} 3$ & $\mathrm{X} 3->\mathrm{X} 1$ & $\mathrm{X} 2->\mathrm{X} 3$ & $\mathrm{X} 3->\mathrm{X} 2$ \\
\hline $\mathrm{X} 2: V R P^{B T Z} ; \mathrm{X} 3: L M^{N Y S E}$ & 0.8755 & 0.0000 & 0.0010 & 0.4253 & 0.1185 & 0.1715 \\
$\mathrm{X}$ : $V R P^{B T Z} ; \mathrm{X} 3: L M^{S P 500}$ & 0.8608 & 0.0000 & 0.0325 & 0.7813 & 0.5928 & 0.6317 \\
$\mathrm{X} 2: V R P^{C W} ; \mathrm{X} 3: L M^{N Y S E}$ & 0.6036 & 0.0000 & 0.0020 & 0.1140 & 0.0743 & 0.6638 \\
$\mathrm{X} 2: V R P^{C W} ; \mathrm{X} 3: L M^{S P 500}$ & 0.5014 & 0.0000 & 0.0368 & 0.3498 & 0.0020 & 0.8722 \\
$\mathrm{X} 2: V R P^{D Y} ; \mathrm{X}$ : $L M^{N Y S E}$ & 0.1683 & 0.0000 & 0.0040 & 0.4389 & 0.0669 & 0.5798 \\
$\mathrm{X} 2: V R P^{D Y} ; \mathrm{X} 3: L M^{S P 500}$ & 0.1103 & 0.0000 & 0.0598 & 0.1459 & 0.0221 & 0.4742 \\
\hline \hline
\end{tabular}

This table summarizes the $p$-value of the chi-square statistics for the Toda-Yamamoto Granger non-causality test with control variables (PD, PE, DFSP, TMSP, RREL and CAY) between the stock returns and Liu (2006) liquidity measure, and between the VRP and Liu (2006) liquidity measure. The analysis uses monthly data for the full sample from January 1990 to December 2018. 
Table 9. VRP, illiquidity, and the four systematic factors

Panel A. VRP \& the four systematic factors $\left(R_{m}-R_{f}, S M B, H M L\right.$ and $\left.M O M\right)$

\begin{tabular}{c|c|cc|cc|cc}
\hline \hline \multirow{3}{*}{$\mathrm{X} 2$} & $\mathrm{X} 1$ & \multicolumn{2}{|c|}{$V R P^{B T Z}$} & \multicolumn{2}{c|}{$V R P^{C W}$} & \multicolumn{2}{c}{$V R P^{D Y}$} \\
\hline \multirow{5}{*}{$R_{m}-R_{f}$} & Sample period & $\mathrm{X} 1->\mathrm{X} 2$ & $\mathrm{X} 2->\mathrm{X} 1$ & $\mathrm{X} 1->\mathrm{X} 2$ & $\mathrm{X} 2->\mathrm{X} 1$ & $\mathrm{X} 1->\mathrm{X} 2$ & $\mathrm{X} 2->\mathrm{X} 1$ \\
& $1990-2018$ & 0.0000 & 0.7861 & 0.0000 & 0.1321 & 0.0009 & 0.2764 \\
& $1990-2012$ & 0.0000 & 0.8390 & 0.0000 & 0.3054 & 0.0024 & 0.3979 \\
& $1992-2014$ & 0.0000 & 0.7900 & 0.0000 & 0.2473 & 0.0037 & 0.3415 \\
& $1994-2016$ & 0.0000 & 0.7605 & 0.0000 & 0.2452 & 0.0028 & 0.3278 \\
& $1996-2018$ & 0.0000 & 0.7741 & 0.0000 & 0.3090 & 0.0039 & 0.2496 \\
\hline \multirow{5}{*}{ SMB } & $1990-2018$ & 0.4406 & 0.1232 & 0.0262 & 0.1235 & 0.0169 & 0.9841 \\
& $1990-2012$ & 0.4985 & 0.2270 & 0.0489 & 0.0815 & 0.0542 & 0.9490 \\
& $1992-2014$ & 0.2800 & 0.4068 & 0.0916 & 0.1417 & 0.2394 & 0.8191 \\
& $1994-2016$ & 0.2898 & 0.3159 & 0.0393 & 0.1165 & 0.0560 & 0.6984 \\
& $1996-2018$ & 0.3265 & 0.2221 & 0.0115 & 0.1024 & 0.0234 & 0.9498 \\
\hline \multirow{5}{*}{$H M L$} & $1990-2018$ & 0.0180 & 0.0316 & 0.0001 & 0.1733 & 0.0002 & 0.4932 \\
& $1990-2012$ & 0.0468 & 0.0181 & 0.0004 & 0.1472 & 0.0001 & 0.4321 \\
& $1992-2014$ & 0.0076 & 0.0164 & 0.0002 & 0.1126 & 0.0005 & 0.7369 \\
& $1994-2016$ & 0.0069 & 0.0227 & 0.0001 & 0.1579 & 0.0002 & 0.6261 \\
& $1996-2018$ & 0.0130 & 0.1080 & 0.0001 & 0.1703 & 0.0008 & 0.5498 \\
\hline \multirow{5}{*}{ MOM } & $1990-2018$ & 0.0235 & 0.2698 & 0.0051 & 0.2238 & 0.0003 & 0.2805 \\
& $1990-2012$ & 0.0145 & 0.3602 & 0.0076 & 0.2220 & 0.0000 & 0.1929 \\
& $1992-2014$ & 0.0133 & 0.1485 & 0.0155 & 0.1805 & 0.0000 & 0.2256 \\
& $1994-2016$ & 0.0407 & 0.1761 & 0.0091 & 0.3197 & 0.0000 & 0.1750 \\
& $1996-2018$ & 0.0492 & 0.4034 & 0.0106 & 0.2697 & 0.0012 & 0.3847 \\
\hline
\end{tabular}

Panel B: ILLIQ \& the four systematic factors $\left(R_{m}-R f, S M B, H M L\right.$ and $\left.M O M\right)$

\begin{tabular}{c|c|cc|cc}
\hline \hline & $\mathrm{X} 1$ & \multicolumn{2}{|c|}{ ILLIQ $^{\text {NYSE }}$} & \multicolumn{2}{c}{ ILLIQ $^{\text {SP500 }}$} \\
\hline $\mathrm{X} 2$ & Sample period & $\mathrm{X} 1->\mathrm{X} 2$ & $\mathrm{X} 2->\mathrm{X} 1$ & $\mathrm{X} 1->\mathrm{X} 2$ & $\mathrm{X} 2->\mathrm{X} 1$ \\
\hline \multirow{5}{*}{$R_{m}-R_{f}$} & $1990-2018$ & 0.5007 & 0.0000 & 0.2928 & 0.0000 \\
& $1990-2012$ & 0.9420 & 0.0000 & 0.2562 & 0.0000 \\
& $1992-2014$ & 0.6895 & 0.0000 & 0.7998 & 0.0000 \\
& $1994-2016$ & 0.7288 & 0.0000 & 0.8567 & 0.0000 \\
& $1996-2018$ & 0.2030 & 0.0000 & 0.5648 & 0.0000 \\
\hline \multirow{3}{*}{$S M B$} & $1990-2018$ & 0.0600 & 0.0016 & 0.0270 & 0.3229 \\
& $1990-2012$ & 0.0513 & 0.0241 & 0.0312 & 0.9712 \\
& $1992-2014$ & 0.0635 & 0.0882 & 0.2804 & 0.8991 \\
& $1994-2016$ & 0.1345 & 0.1102 & 0.1663 & 0.9210 \\
& $1996-2018$ & 0.2190 & 0.0590 & 0.1604 & 0.7632 \\
\hline \multirow{5}{*}{$H M L$} & $1990-2018$ & 0.1485 & 0.4093 & 0.0183 & 0.2683 \\
& $1990-2012$ & 0.1108 & 0.2406 & 0.0181 & 0.2467 \\
& $1992-2014$ & 0.1168 & 0.3329 & 0.0138 & 0.3671 \\
& $1994-2016$ & 0.2676 & 0.7816 & 0.0438 & 0.6183 \\
& $1996-2018$ & 0.3138 & 0.6890 & 0.0507 & 0.6267 \\
\hline \multirow{5}{*}{ MOM } & $1990-2018$ & 0.9676 & 0.0000 & 0.2695 & 0.0000 \\
& $1990-2012$ & 0.9107 & 0.0000 & 0.2012 & 0.0000 \\
& $1992-2014$ & 0.3170 & 0.0000 & 0.2730 & 0.0000 \\
& $1994-2016$ & 0.8567 & 0.0000 & 0.2912 & 0.0000 \\
\hline \hline
\end{tabular}

This table summarizes the $p$-value of the chi-square statistics for the Toda-Yamamoto Granger non-causality tests between $V R P$ and risk factors $\left(R_{m}-R_{f}, S M B, H M L\right.$ and $\left.M O M\right)$ (Panel A), and between illiquidity and same risk factors (Panel B). The analysis uses monthly data from the full sample period from January 1990 to December 2018, and four sub-samples from January 1990 to December 2012, January 1992 to December 2014, January 1994 to December 2016, and January 1996 to December 2018. 
Table 10. VRP, illiquidity, and the four systematic factors with control variables

Panel A. VRP \& the four systematic factors $\left(R_{m}-R_{f}, S M B, H M L\right.$ and $\left.M O M\right)$

\begin{tabular}{c|c|cc|cc|cc}
\hline \hline \multirow{3}{*}{$\mathrm{X} 2$} & $\mathrm{X} 1$ & \multicolumn{2}{|c|}{$V R P^{B T Z}$} & \multicolumn{2}{c|}{$V R P^{C W}$} & \multicolumn{2}{c}{$V R P^{D Y}$} \\
\hline \multirow{5}{*}{$R_{m}-R_{f}$} & Sample period & $\mathrm{X} 1->\mathrm{X} 2$ & $\mathrm{X} 2->\mathrm{X} 1$ & $\mathrm{X} 1->\mathrm{X} 2$ & $\mathrm{X} 2->\mathrm{X} 1$ & $\mathrm{X} 1->\mathrm{X} 2$ & $\mathrm{X} 2->\mathrm{X} 1$ \\
\hline & $1990-2018$ & 0.0000 & 0.8361 & 0.0000 & 0.6514 & 0.0000 & 0.2656 \\
& $1990-2012$ & 0.0000 & 0.8504 & 0.0000 & 0.2956 & 0.0001 & 0.2077 \\
& $1992-2014$ & 0.0000 & 0.1424 & 0.0000 & 0.5407 & 0.0001 & 0.1296 \\
& $1994-2016$ & 0.0000 & 0.1563 & 0.0000 & 0.7945 & 0.0001 & 0.1300 \\
& $1996-2018$ & 0.0000 & 0.6079 & 0.0000 & 0.8517 & 0.0001 & 0.2405 \\
\hline \multirow{5}{*}{$S M B$} & $1990-2018$ & 0.6872 & 0.2295 & 0.0436 & 0.0166 & 0.0016 & 0.8717 \\
& $1990-2012$ & 0.9520 & 0.3340 & 0.0847 & 0.0493 & 0.0041 & 0.9806 \\
& $1992-2014$ & 0.8066 & 0.5056 & 0.0800 & 0.0406 & 0.0035 & 0.9337 \\
& $1994-2016$ & 0.6685 & 0.4041 & 0.0707 & 0.0334 & 0.0015 & 0.8932 \\
& $1996-2018$ & 0.5871 & 0.3203 & 0.0566 & 0.0329 & 0.0034 & 0.8549 \\
\hline \multirow{5}{*}{$H M L$} & $1990-2018$ & 0.0068 & 0.1080 & 0.0004 & 0.1844 & 0.0000 & 0.4468 \\
& $1990-2012$ & 0.0034 & 0.1183 & 0.0012 & 0.1456 & 0.0000 & 0.5007 \\
& $1992-2014$ & 0.0060 & 0.1016 & 0.0003 & 0.1500 & 0.0000 & 0.5493 \\
& $1994-2016$ & 0.0011 & 0.2190 & 0.0002 & 0.1203 & 0.0000 & 0.6486 \\
& $1996-2018$ & 0.0011 & 0.2966 & 0.0006 & 0.1708 & 0.0000 & 0.5661 \\
\hline \multirow{5}{*}{ MOM } & $1990-2018$ & 0.0026 & 0.2842 & 0.0032 & 0.3954 & 0.0035 & 0.5174 \\
& $1990-2012$ & 0.0014 & 0.3787 & 0.0024 & 0.1507 & 0.0133 & 0.8063 \\
& $1992-2014$ & 0.0002 & 0.3718 & 0.0009 & 0.2188 & 0.0042 & 0.7986 \\
& $1994-2016$ & 0.0014 & 0.3361 & 0.0012 & 0.4510 & 0.0022 & 0.1449 \\
& $1996-2018$ & 0.0037 & 0.3935 & 0.0049 & 0.5065 & 0.0054 & 0.4195 \\
\hline
\end{tabular}

Panel B. ILLIQ \& the four systematic factors $\left(R_{m}-R_{f}, S M B, H M L\right.$ and $\left.M O M\right)$

\begin{tabular}{c|c|cc|cc}
\hline \hline & $\mathrm{X} 1$ & \multicolumn{2}{|c|}{$I L L I Q^{N Y S E}$} & \multicolumn{2}{c}{ ILLIQ $Q^{S P 500}$} \\
\hline $\mathrm{X} 2$ & Sample period & $\mathrm{X} 1->\mathrm{X} 2$ & $\mathrm{X} 2->\mathrm{X} 1$ & $\mathrm{X} 1->\mathrm{X} 2$ & $\mathrm{X} 2->\mathrm{X} 1$ \\
\hline \multirow{3}{*}{$R_{m}-R_{f}$} & $1990-2018$ & 0.5225 & 0.0000 & 0.2547 & 0.0000 \\
& $1990-2012$ & 0.7981 & 0.0000 & 0.2538 & 0.0000 \\
& $1992-2014$ & 0.3203 & 0.0000 & 0.7092 & 0.0000 \\
& $1994-2016$ & 0.4153 & 0.0000 & 0.7487 & 0.0000 \\
& $1996-2018$ & 0.3414 & 0.0000 & 0.6622 & 0.0000 \\
\hline \multirow{3}{*}{$S M B$} & $1990-2018$ & 0.0822 & 0.0049 & 0.1310 & 0.5000 \\
& $1990-2012$ & 0.0612 & 0.0194 & 0.1028 & 0.6957 \\
& $1992-2014$ & 0.0452 & 0.0264 & 0.3686 & 0.7607 \\
& $1994-2016$ & 0.1471 & 0.0503 & 0.1276 & 0.7374 \\
& $1996-2018$ & 0.2952 & 0.0319 & 0.1353 & 0.8021 \\
\hline \multirow{3}{*}{$H M L$} & $1990-2018$ & 0.2849 & 0.3456 & 0.0389 & 0.2644 \\
& $1990-2012$ & 0.2090 & 0.1842 & 0.0367 & 0.2774 \\
& $1992-2014$ & 0.2063 & 0.3170 & 0.0254 & 0.4163 \\
& $1994-2016$ & 0.2495 & 0.5454 & 0.0262 & 0.9441 \\
& $1996-2018$ & 0.3372 & 0.7987 & 0.0329 & 0.8979 \\
\hline \multirow{3}{*}{ MOM } & $1990-2018$ & 0.5427 & 0.0000 & 0.6216 & 0.0000 \\
& $1990-2012$ & 0.5248 & 0.0000 & 0.4718 & 0.0000 \\
& $1992-2014$ & 0.3147 & 0.0000 & 0.5174 & 0.0000 \\
& $1994-2016$ & 0.3142 & 0.0000 & 0.5533 & 0.0000 \\
& $1996-2018$ & 0.4052 & 0.0000 & 0.4046 & 0.0000 \\
\hline \hline
\end{tabular}

This table summarizes the $p$-value of the chi-square statistics for the Toda-Yamamoto Granger non-causality tests with control variables ( $P D, P E, D F S P, T M S P, R R E L$ and $C A Y$ ) between VRP and the four systematic factors $\left(R_{m}-R_{f}, S M B, H M L\right.$ and $\left.M O M\right)$ (Panel A), and between illiquidity and the same four factors (Panel B). The analysis uses monthly data from the full sample period from January 1990 to December 2018, and four subsamples from January 1990 to December 2012, January 1992 to December 2014, January 1994 to December 2016, and January 1996 to December 2018. 